\title{
HFIR SiC-SiC Composite Clad Tube Bowing Test: Pre-Irradiation Characterization
}

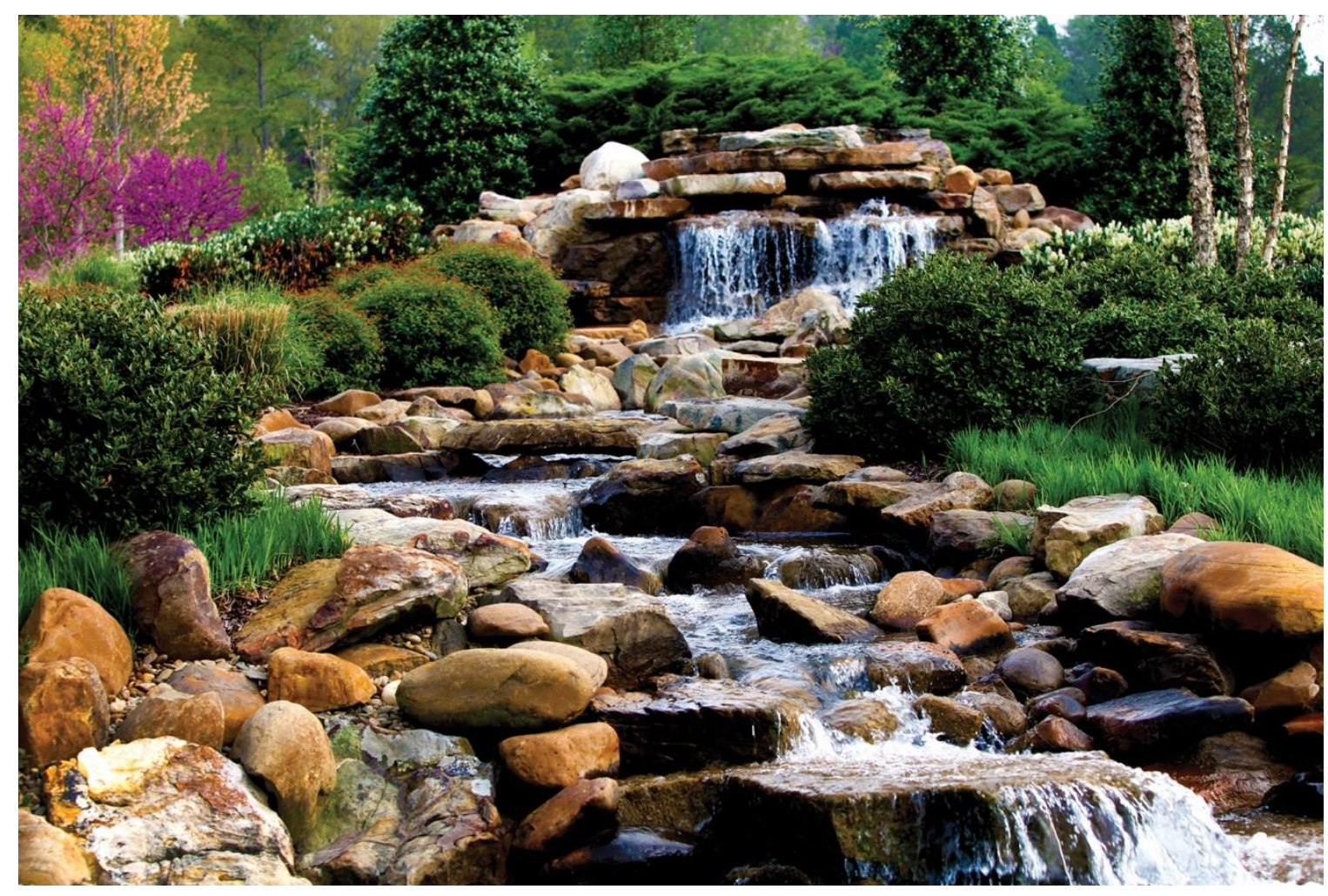

Josina W. Geringer

Chris Petrie

Adam James

Takaaki Koyanagi

Christian Deck

Yutai Katoh

August 2021 


\title{
DOCUMENT AVAILABILITY
}

Reports produced after January 1, 1996, are generally available free via US Department of Energy (DOE) SciTech Connect.

Website www.osti.gov

Reports produced before January 1, 1996, may be purchased by members of the public from the following source:

\author{
National Technical Information Service \\ 5285 Port Royal Road \\ Springfield, VA 22161 \\ Telephone 703-605-6000 (1-800-553-6847) \\ TDD 703-487-4639 \\ Fax 703-605-6900 \\ E-mail info@ntis.gov \\ Website http://classic.ntis.gov/
}

Reports are available to DOE employees, DOE contractors, Energy Technology Data Exchange representatives, and International Nuclear Information System representatives from the following source:

Office of Scientific and Technical Information

PO Box 62

Oak Ridge, TN 37831

Telephone 865-576-8401

Fax 865-576-5728

E-mail reports@osti.gov

Website http://www.osti.gov/

This report was prepared as an account of work sponsored by an agency of the United States Government. Neither the United States Government nor any agency thereof, nor any of their employees, makes any warranty, express or implied, or assumes any legal liability or responsibility for the accuracy, completeness, or usefulness of any information, apparatus, product, or process disclosed, or represents that its use would not infringe privately owned rights. Reference herein to any specific commercial product, process, or service by trade name, trademark, manufacturer, or otherwise, does not necessarily constitute or imply its endorsement, recommendation, or favoring by the United States Government or any agency thereof. The views and opinions of authors expressed herein do not necessarily state or reflect those of the United States Government or any agency thereof. 
Material Science and Technology Division

\title{
HFIR SIC-SIC COMPOSITE CLAD TUBE BOWING TEST: PRE-IRRADIATION CHARACTERIZATION
}

\author{
Josina W. Geringer \\ Chris Petrie \\ Adam James \\ Takaaki Koyanagi \\ Christian Deck \\ Yutai Katoh
}

August 2021

Prepared by

OAK RIDGE NATIONAL LABORATORY

Oak Ridge, TN 37831-6283

managed by

UT-BATTELLE, LLC

for the

US DEPARTMENT OF ENERGY

under contract DE-AC05-00OR22725 



\section{CONTENTS}

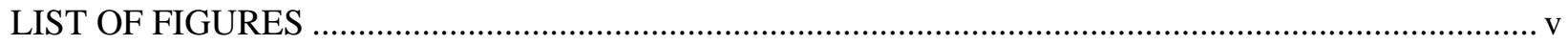

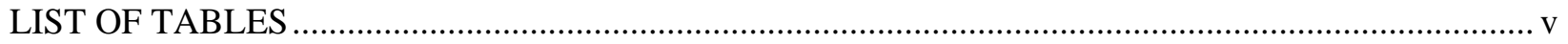

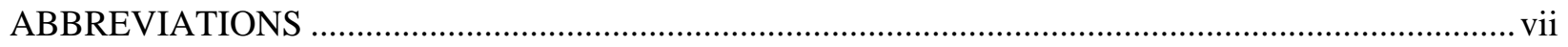

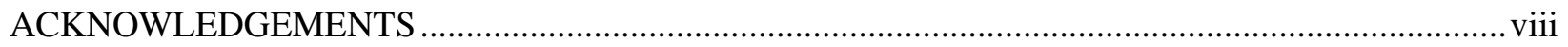

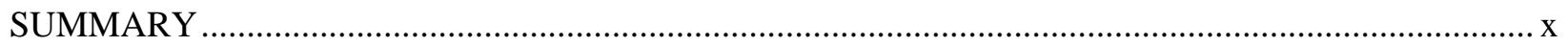

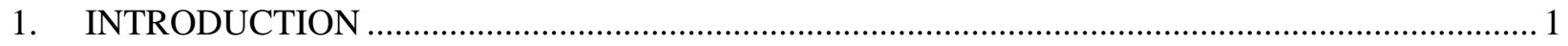

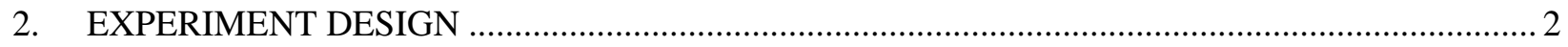

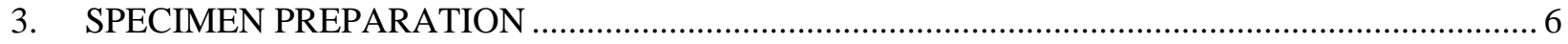

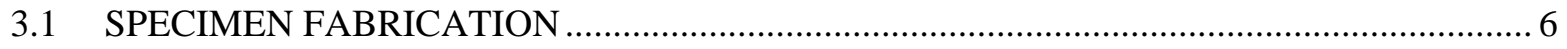

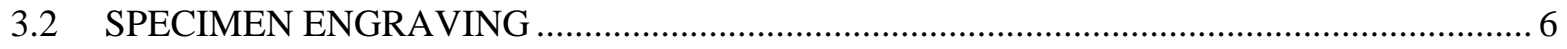

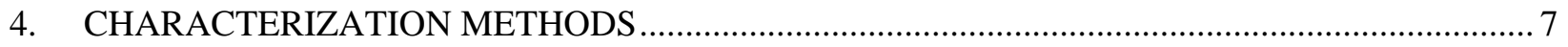

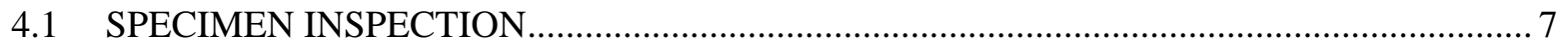

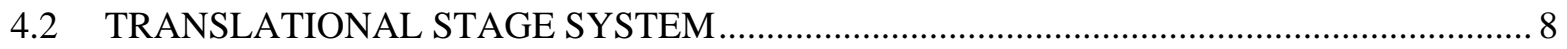

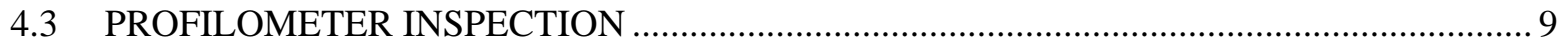

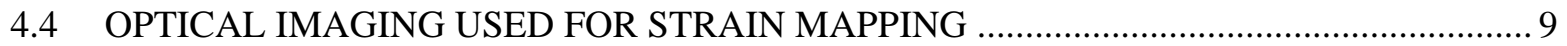

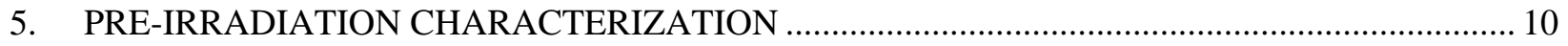

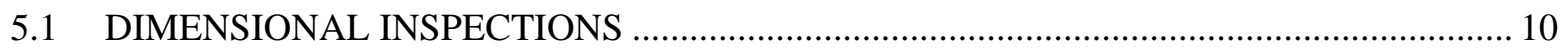

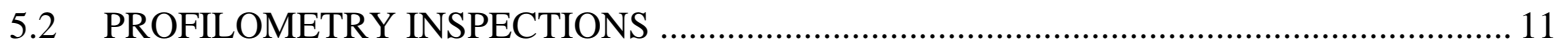

5.3 FIDUCIAL MARKER RECORDINGS FOR LOCAL STRAIN MAPPING ….................... 13

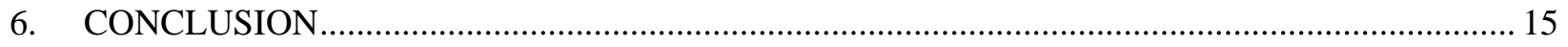

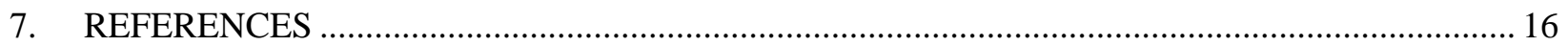

APPENDIX A. INSPECTION RESULTS OF THE STEEL CONTROL SPECIMEN ......................... A-1

APPENDIX B. MEASURED LOCATIONS OF ENGRAVED MARKERS OF THE SIC-SIC

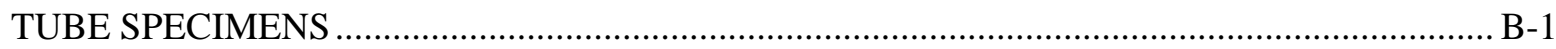




\section{LIST OF FIGURES}

Figure 1. Experiment positions in HFIR.

Figure 2. The (a) design and (b) assembly of the $380 \mathrm{~mm}$ long tube specimens in the channel box experiment.

Figure 3. Dose per cycle (EOC) as a function of axial position $X$ with radial position $Y$ as a parameter.

Figure 4. Spatial swelling gradients over the experiment at core midplane after one irradiation cycle.

Figure 5. Simulated displacement (in meters) after one HFIR cycle. The visual deformation of the structures are artificially magnified by a factor 10 .

Figure 6. Simulated maximum tube specimen displacement in the $Y$ direction $\left(U_{Y}\right)$ and bowing vs. number of HFIR cycles.

Figure 7. A 2D radiograph taken from T01 and T22 showing the fiber architecture pattern. ................... 6

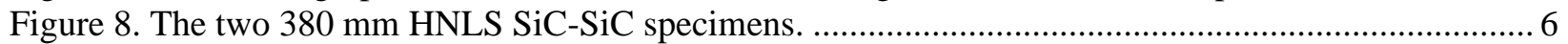

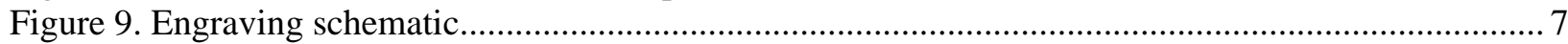

Figure 10. Example of the engraved specimen T01 (bottom) showing the enlarged section of the engraved ID 01 (top left) with fiducial marks, as well as the dashed lines and associated perimeter number (top right).

Figure 11. (a) Dimensional inspection labeling points for length measurements, (b) diameter measurements around the perimeter, and (c) diameter measurements over the span of the length.

Figure 12. Custom translational stage system setup.

Figure 13. SiC-SiC tube specimen positioned for (a) 2D profile scans with the Keyence Optical Micrometer and (b) local strain measurements using a Dino-Lite high-magnification microscope.

Figure 14. Diameter plots of the SiC-SiC tube specimens (a) T01 and (b) T22 for the eight respective scans.

Figure 15. The transformed plot of SiC-SiC tube specimen, T01, showing the (a) top profile and

(b) corresponding bottom profile of the eight respective scans.

Figure 16. The transformed plot of $\mathrm{SiC}-\mathrm{SiC}$ tube specimen, T22 showing the (a) top profile and (b) corresponding bottom profile of the eight respective scans.

Figure 17. (a) Example of a stitched image section of specimen T01 showing the (b) stacked images created of the engraved fiducial markings T01-1-X1 and T01-1-X2.

Figure 18. The recorded pre-irradiation fiducial marker plots for specimen T01 (left) and T22 (right) showing markers respective with the associated perimeter number's starting point.

\section{LIST OF TABLES}

Table 1. Summary of nominal dimensions by dimensional inspection in millimeters on T01 and T22 SiC-SiC tube specimens and control specimen AB.

Table 2. Straightness measurements of the SiC-SiC tube specimens T01 and T22 in millimeters. 11 



\section{ABBREVIATIONS}

\begin{abstract}
$\mathrm{Al}$
DOE

EOC

HFIR

HNLS

ORNL

$\mathrm{SiC}-\mathrm{SiC}$

VXF

$\mathrm{Zr}$
\end{abstract}

\author{
Aluminum \\ U.S. Department of Energy \\ end of cycle \\ High Flux Isotope Reactor \\ Hi-Nicalon Type-S \\ Oak Ridge National Laboratory \\ silicon carbide - silicon carbide \\ Vertical Experiment Facility \\ zirconium
}




\section{ACKNOWLEDGEMENTS}

This study was supported by the US Department Energy's (DOE's) Office of Nuclear Energy for the Advanced Fuels Campaign of the Nuclear Technology R\&D program and the Westinghouse Electric Corporation/General Atomics Funding Opportunity Announcement program under contact DE-AC0500OR22725 with Oak Ridge National Laboratory (ORNL) managed by UT Battelle LLC. A portion of this research used resources at the High Flux Isotope Reactor, a DOE Office of Science User Facility operated by ORNL. Annabelle Le Coq assisted with specimen preparation, and David Bryant (ORNL) performed the specimen engraving and experiment assembly. T. M. (Tom) Rosseel and Lauren Garrison (ORNL) performed technical reviews of the report and provided helpful comments. 


\section{SUMMARY}

This report describes the pre-irradiation characterization of the $\mathrm{SiC}-\mathrm{SiC}$ composite clad tube bowing experiment that will be irradiated in the High Flux Isotope Reactor (HFIR). There are concerns that SiC$\mathrm{SiC}$ fuel cladding in light water reactors could undergo bowing because of the non-uniform fast neutron flux profiles. This experiment is combined with the SiC-SiC channel box experiment, which has similar concerns regarding control blade movements in boiling water reactors. The HFIR experiment aims to validate the predicted deformation and stresses in the composite clad specimen after the exposure of fast neutron flux gradients. Significant radial fast neutron flux gradients that exist in the permanent reflector of HFIR were thoroughly characterized by using detailed 3D neutronic calculations. The 3D displacement damage dose rate profile and the resulting volumetric swelling in $\mathrm{SiC}$ were used as inputs to structural analyses to determine the predicted deformation that will affect the specimens.

The tube specimens were characterized by using traditional dimensional inspection and surface profilometry to provide detailed information regarding the pre-irradiation condition as the first step to evaluate the radiation-induced deformation. Furthermore, fine engraving markers were inscribed along all outer surfaces of the specimen and mapped by using a digital microscope and a multidimensional stage. This allows marker spacings to be accurately measured and compared with similar measurements that will be made post-irradiation to provide local radiation-induced strain mapping. The experiment successfully completed two HFIR cycle irradiations, cycles 492 and 493, which finished on July 25, 2021. 


\section{INTRODUCTION}

This report summarizes the results of the pre-irradiation characterization of the SiC-SiC composite clad tube specimens from the joint research venture between Westinghouse-General Atomics and the Advanced Fuels Campaign Program. This report studied the effect of bowing due to the exposure of fast neutron flux gradient along the height of the reactor. The irradiation was performed in the flux trap of the Oak Ridge National Laboratory High Flux Isotope Reactor (HFIR). This report includes the basics of the program (i.e., material, properties, and irradiation) and the results of the predicted property changes due to different irradiation conditions (i.e., temperature and total fluence).

SiC-SiC composites undergo temperature-dependent swelling under fast neutron irradiation $(\mathrm{E}>0.1 \mathrm{MeV})$ [1]. Under flux gradients or non-isothermal irradiation, nonuniform swelling in SiC-SiC fuel cladding is expected to lead to lateral bowing or distortion, as previously shown [2]. An experiment was designed in HFIR to separate the temperature-dose-dependent effects that target a steady coolant temperature to validate the modeled lateral bowing as a result of the fast neutron exposure over the height (i.e., axial profile) of the reactor core.

The work presented herein primarily focuses on the anticipated distortion of a SiC-SiC composite tube for light water reactor fuel cladding applications. The evaluation is based on the composite behavior that surrounds the $\mathrm{UO}_{2}$ fuel element. A typical fuel clad component is $\sim 10 \mathrm{~mm}$ in diameter and $\sim 4 \mathrm{~m}$ long. Because of temperature-dependent swelling and fast neutron flux gradients, bowing of the cladding components can obstruct control rod insertion or block coolant channels.

This report is a partial reporting of the combined channel box irradiation experiment, which investigated the lateral bowing of the miniature channel box used in boiling water reactors, as well as cladding tubes used in light water reactors due to differential swelling. The stress analysis and flux calculations were reported elsewhere $[2,3]$.

Promising material properties - such as low neutron absorption, excellent high-temperature strength, maintained mechanical properties, and chemical inertness - and exceptional resistance to steam oxidation at high temperatures makes $\mathrm{SiC}-\mathrm{SiC}$ an ideal candidate material to replace current $\mathrm{Zr}$-alloy materials. However, SiC swelling and thermal conductivity are critical parameters for the feasibility of the application as determined by Lee [4] after modeling a multilayered SiC clad. In another study, Singh investigated the thermal-mechanical behavior of SiC-SiC and the combined interaction of the fuel rod [2]. Lee also concluded that irradiation-induced swelling in the SiC-SiC clad contributes significantly to the stress development model. The strain associated with the differential swelling as a result of differential flux and temperature profile dominate the stress profile in the cladding.

The dose-dependent swelling effects is well known and well documented [5-10]. Using the swelling rate model [9], Katoh [10] separated the swelling effects as a function of dose and temperature.

Separating the induced temperature-dose effects - even with rudimentary methods - allows for independent property characterization that can be validated through experimentation. It also provides a baseline to model the lateral bowing due to the fast flux gradient.

The purpose of this experiment is to examine the lateral bowing behavior of the composite clad tube caused by the differential swelling under fast neutron irradiation at a $50-60^{\circ} \mathrm{C}$ coolant temperature. This report discusses the pre-irradiation work performed to characterize the $\mathrm{SiC}-\mathrm{SiC}$ composite tube specimens. 


\section{EXPERIMENT DESIGN}

The irradiation experiment was designed for HFIR's large Vertical Experiment Facility (VXF) in the HFIR reflector, as shown in Figure 1 [11]. The experiment design allows the specimens to be directly cooled by the reactor coolant, which flows through the experiment from top to bottom. The coolant temperature range is between 50 to $60^{\circ} \mathrm{C}$.

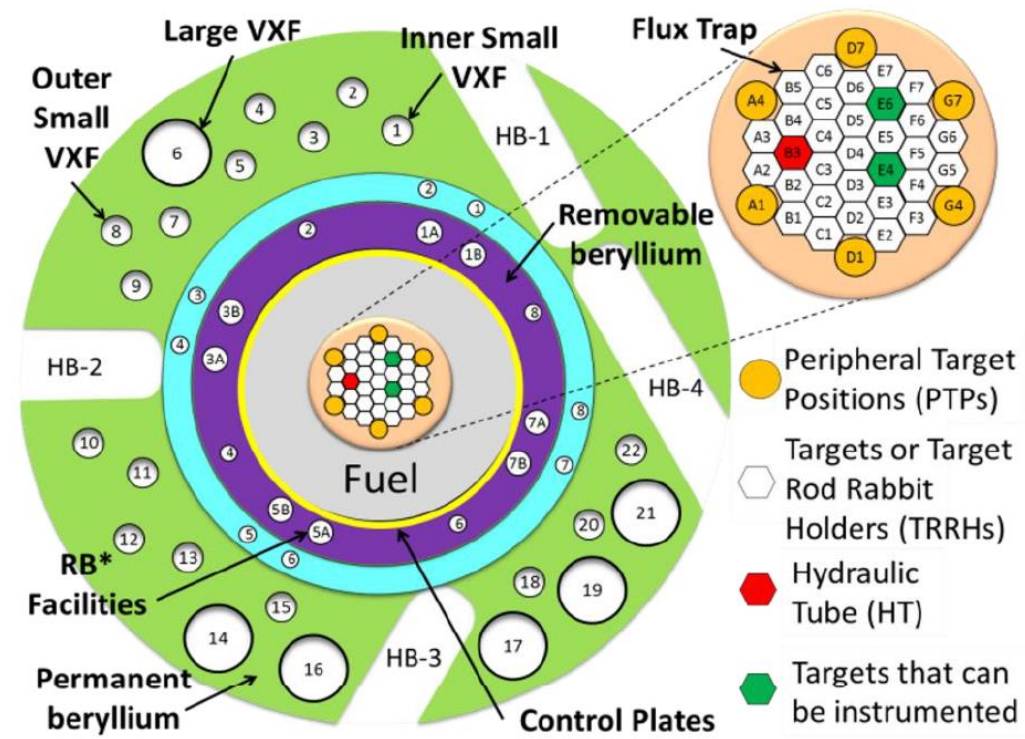

Figure 1. Experiment positions in HFIR.

Figure 2 shows the irradiation experiment design and assembly. The irradiation vehicle is a two-piece Al holder that results in a cylindrical assembly with internal cutouts for the specimens when welded together. The orifice at the bottom of the holder controls the coolant flow rate that enters from the top of the experiment. The miniature channel box and tube specimens are assembled inside the holder cutout. The nominal dimensions of the miniature channel box are $30 \mathrm{~mm} \times 30 \mathrm{~mm} \times 380 \mathrm{~mm}$ with a $1.25 \mathrm{~mm}$ thick wall. As previously mentioned, this irradiation is a shared programmatic activity, and the pre-irradiation characterization of the channel box specimen is reported elsewhere [12].

The tube specimens have a prototypic pressurized water reactor cladding diameter of $9.5 \mathrm{~mm}$, a wall thickness of $1 \mathrm{~mm}$, and a length of $380 \mathrm{~mm}$. Two $\mathrm{Al}$ internal supports, lower and upper, are stacked together on either end of the channel box and secured by using a tie rod. The large features at the top and bottom of the support pieces ensure that the channel box remains centered inside the Al holder. Wave springs are placed between the channel box specimen and the supports to keep the channel box centered around the support pieces. The wave springs have minimal stiffness to allow the channel box to bow without applying any significant load or stress on the channel box. Radial holes at the top and bottom of the tube specimens allow them to be secured to the internal supports by using fasteners. The fasteners pass through the tube specimens and slots in the slotted pins, which are welded to the internal supports. This allows the tube specimens to bend and translate axially while maintaining their orientation inside the experiment. The specimens were assembled with their engraved IDs ("01" and "22") pointing toward the bottom of the experiment. Specimen 01 is in the position closer to the core, while tube specimen 22 is positioned further from the core. 
(a)

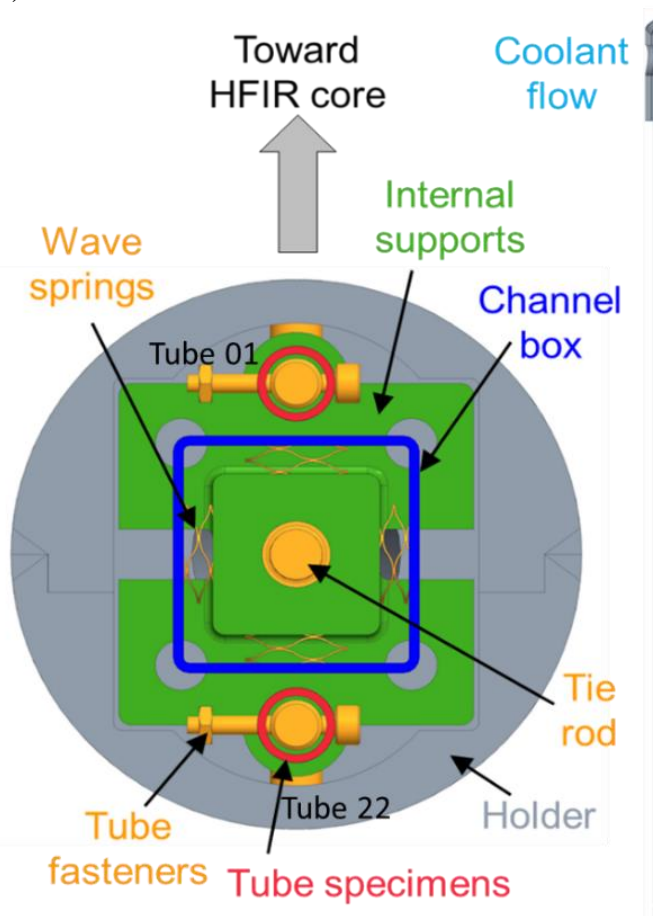

Top section view through center of specimens

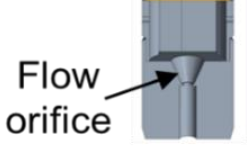

Side section view

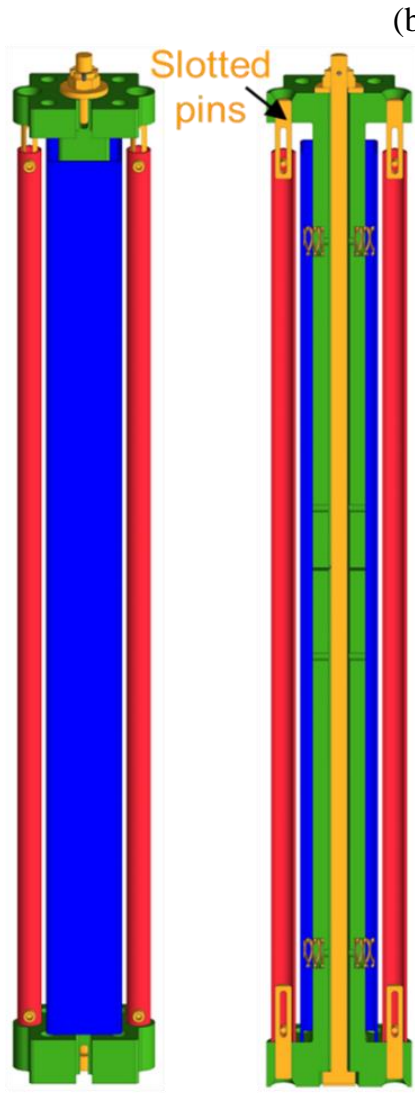

Internals (b)

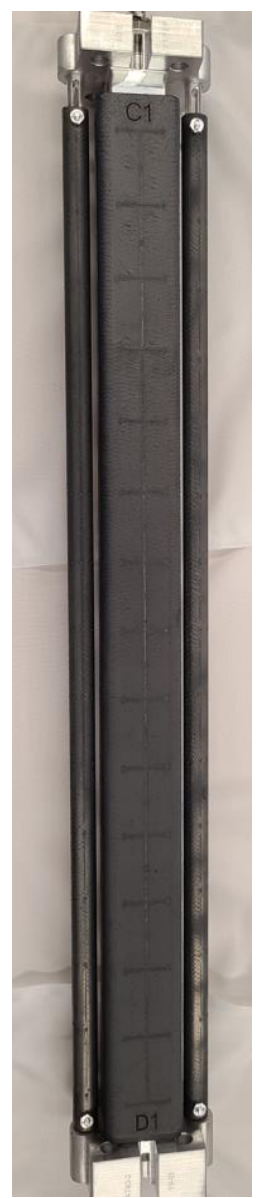

Figure 2. The (a) design and (b) assembly of the $380 \mathrm{~mm}$ long tube specimens in the channel box experiment.

Figure 3 shows the expected dose at the end of cycle (EOC) for various radial distances $(Y)$, assuming the midplane $(Y=0)$ to be the center of the large VXF location. The dose reduces significantly when moving away from the core (decreasing $Y$ ). Beginning-of-cycle and EOC comparisons showed that there were no significant dose differences. The calculated dose is derived from the fast neutron fluence with a relationship where $1 \mathrm{dpa}$ equals $1 \times 10^{25} \mathrm{n} / \mathrm{m}^{2}$, and $E>0.1 \mathrm{MeV}$.

As reported elsewhere [12], the dose was converted to volumetric swelling by using literature data from previous HFIR irradiation experiments performed at the same coolant temperatures. Figure 4 [13] demonstrates the anticipated swelling gradients across the channel box experiment and partially shows the gradient across the tube specimens. The red and blue lines indicate the tube specimen positions relative to the radial midplane $(Y=0)$ in the experiment assembly. The profile shows the midplane position of the core (where $Z=0$ ) after one cycle. 


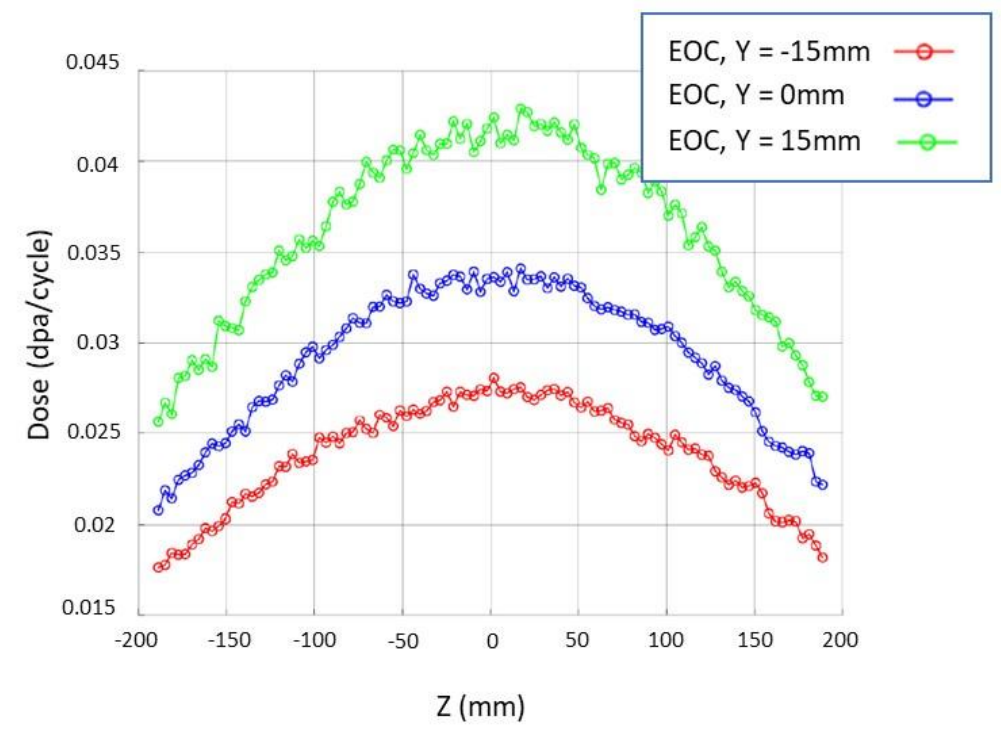

Figure 3. Dose per cycle (EOC) as a function of axial position $X$ with radial position $Y$ as a parameter.

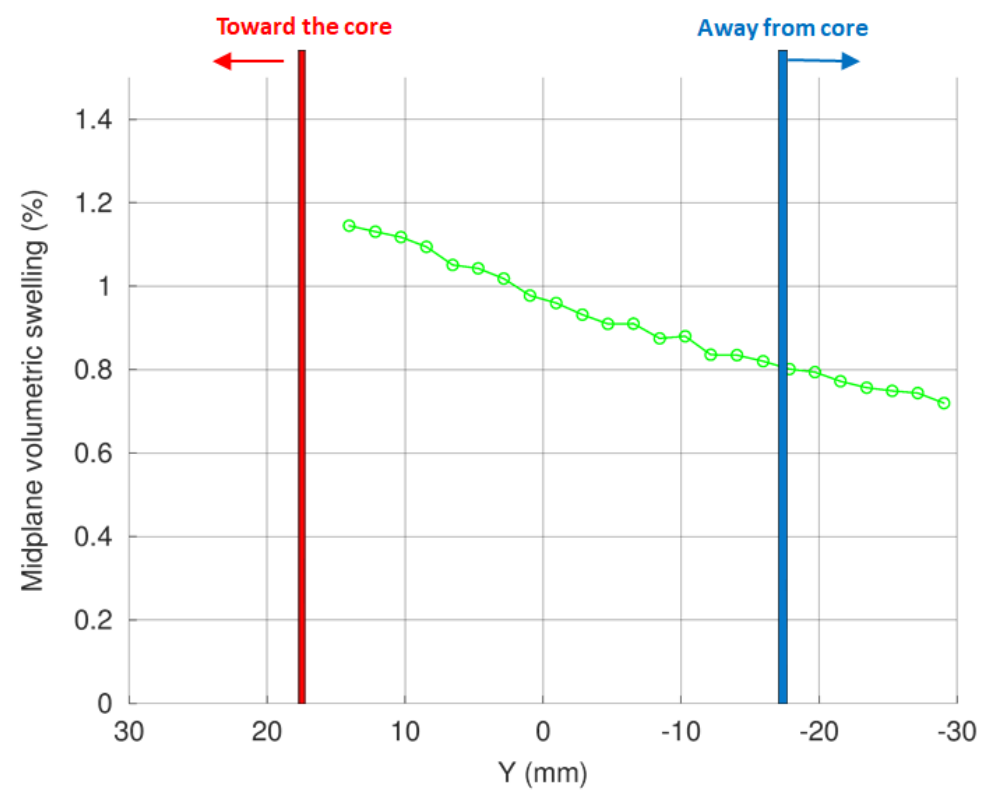

Figure 4. Spatial swelling gradients over the experiment at core midplane after one irradiation cycle. The vertical lines indicate the positions of the tube specimens in the experiment position.

The displacement analysis of the SiC-SiC tube specimens was performed by using the commercial Ansys software. The displacement analysis is based on the calculated temperature and flux boundary conditions mentioned previously. The variation in the volumetric swelling between the front and back of the specimens (when facing the core) creates lateral strain along the length of the specimens. The simulated displacement, $U_{Y}$, (in meters), as illustrated in Figure 5, shows the combined result of the of lateral swelling and bowing effects. The visual illustration is artificially magnified by a factor 10 but the reported scales are the true calculated displacement values. The lateral bow is defined as the maximum lateral displacement for all nodes at a given $Z$ position relative to the maximum lateral displacement at $Z=0 \mathrm{~mm}$ and compensates for swelling so that the lateral displacement will be slightly larger than the anticipated lateral bowing. 


$$
\begin{aligned}
& \text { 3.26e-9 Max } \\
& -6.58 e-5 \\
& -1.32 e-4 \\
& -1.97 e-4 \\
& -2.63 e-4 \\
& -3.29 e-4 \\
& -3.95 e-4 \\
& -4.61 e-4 \\
& -5.27 e-4 \\
& -5.92 e-4 \text { Min }
\end{aligned}
$$

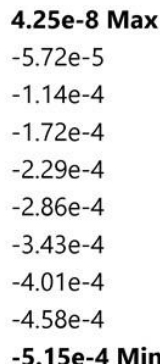

Figure 5. Simulated displacement (in meters) after one HFIR cycle. The visual deformation of the structures are artificially magnified by a factor 10.

From earlier experiments, the volumetric swelling was determined to range from 0.7 to $1.15 \%$ after one HFIR cycle with dose values ranging from 0.02 to 0.04 dpa at coolant temperature. This corresponds to linear strains ranging from 0.23 to $0.38 \%$. After a second HFIR cycle, the volumetric swelling ranges from 1.15 to $1.9 \%$ with dose values ranging from 0.04 to $0.08 \mathrm{dpa}$ at coolant temperature. Figure 6 shows the expected maximum trend of the tube specimen displacement for the radial direction $(Y)$ and the expected bowing to occur after each HFIR cycle.

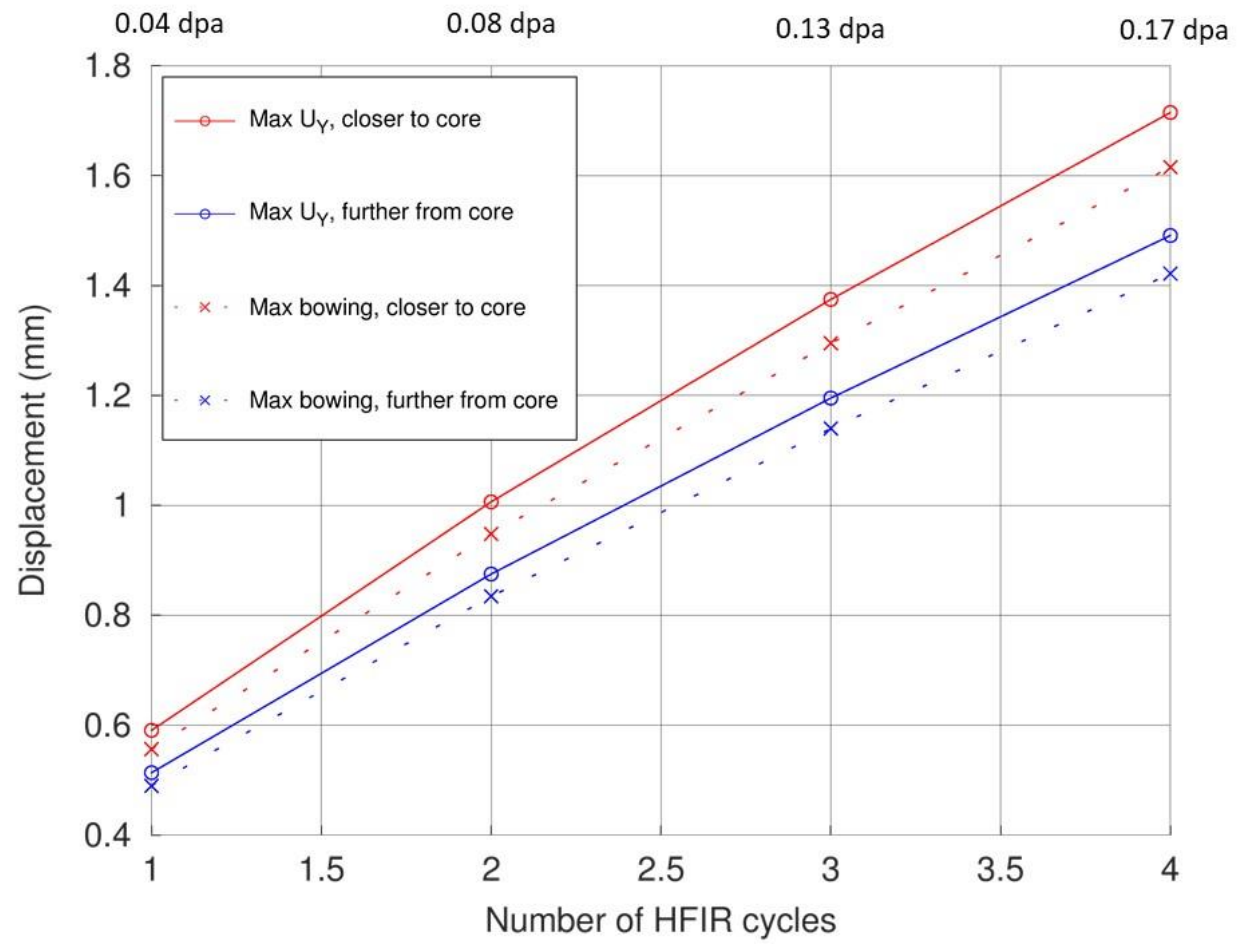

Figure 6. Simulated maximum tube specimen displacement in the $Y$ direction $\left(U_{Y}\right)$ and bowing vs. number of HFIR cycles. 


\section{SPECIMEN PREPARATION}

\subsection{SPECIMEN FABRICATION}

The two SiC-SiC tube specimens with engraved IDs of 01 and 22 were fabricated by General Atomics and are hereafter designated as $T 01$ and T22, respectively. The specimens were fabricated with similar composition and processing. The fabrication used a Hi-Nicalon Type-S (HNLS) SiC fibers with a $150 \mathrm{~nm}$ thick pyrolytic $\mathrm{C}$ interphase surrounded by a $\mathrm{SiC}$ matrix formed by chemical vapor infiltration and a thin outer layer formed by using chemical vapor deposition. The two specimens have the same braided fiber architecture (Figure 7) with a $\pm 50^{\circ}$ braiding angle. The nominal fiber volume fraction was $30-40 \%$. Figure 8 shows the two specimens. Two radial pin holes were machined at the ends of each specimen.
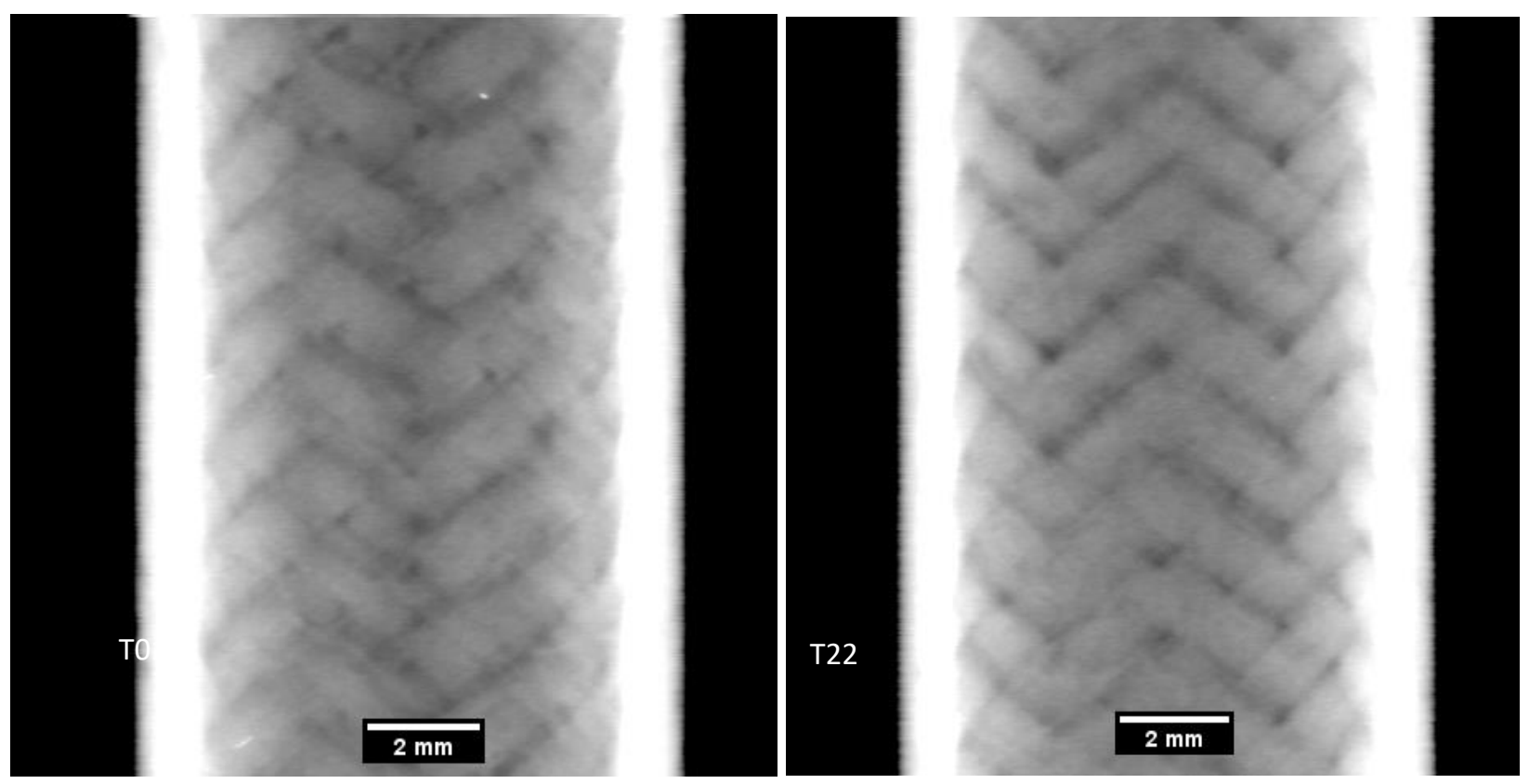

Figure 7. A 2D radiograph taken from $\mathrm{T01}$ and $\mathrm{T} 22$ showing the fiber architecture pattern.

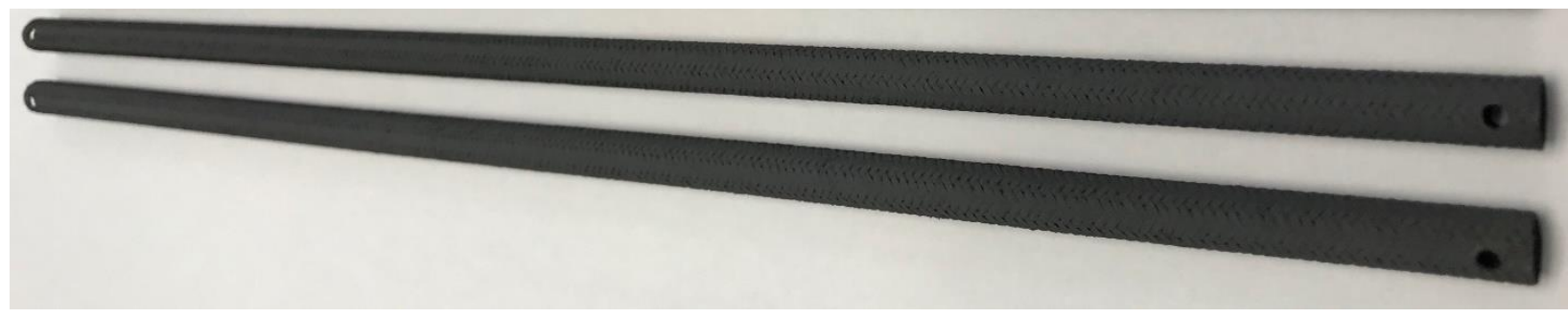

Figure 8. The two $380 \mathrm{~mm}$ HNLS SiC-SiC specimens.

\subsection{SPECIMEN ENGRAVING}

Each specimen was clearly marked to retain orientation and to duplicate setup for measurements before and after irradiation. Each specimen was engraved with eight dashed lines every $45^{\circ}$ along the length of the specimen. Fine fiducial " $x$ " markings separated by $\sim 25 \mathrm{~mm}$, were made in circled locations between the dashed lines, including at the start and end, along the length of each dashed line. The specimens were inscribed with an ID on one end, and a series of numbers 1-8, were engraved around the circumference to identify the individual dashed lines on the other end. This is also referred to as the perimeter number, $P_{x}$, 
used in the remainder of the report. The line width of the fiducial markings was $\sim 30 \mu \mathrm{m}$. The center of each line must be located before and after irradiation to accurately determine displacements. Figure 9 shows the engraved schematic as described, and Figure 10 shows an example of specimen T01 with the $0^{\circ}$ position $\left(\mathrm{P}_{1}\right.$, dashed line 1$)$.
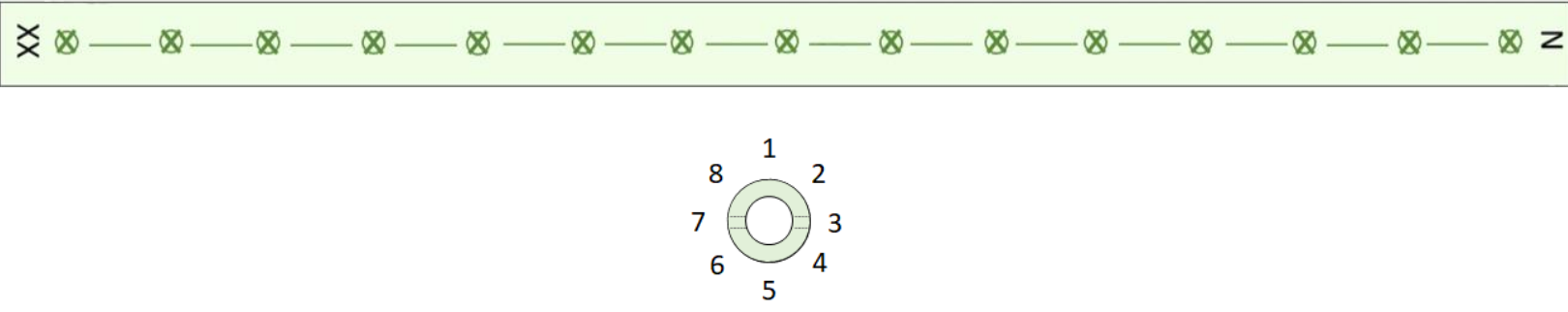

Figure 9. Engraving schematic.

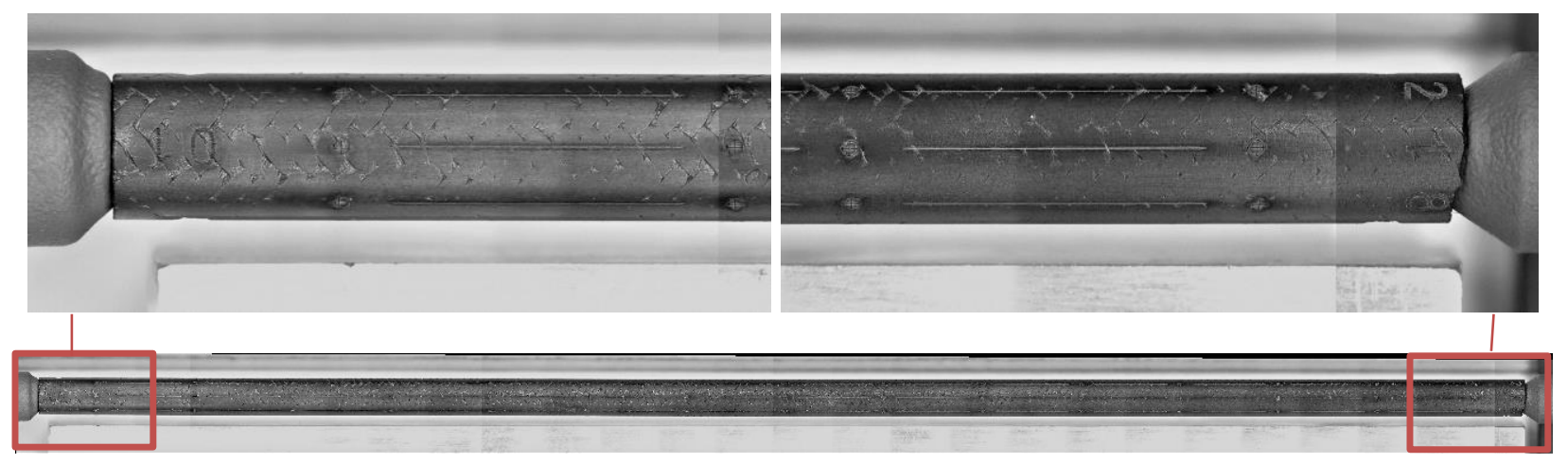

Figure 10. Example of the engraved specimen T01 (bottom) showing the enlarged section of the engraved ID 01 (top left) with fiducial marks, as well as the dashed lines and associated perimeter number (top right).

\section{CHARACTERIZATION METHODS}

\subsection{SPECIMEN INSPECTION}

The specimens were inspected for mass, dimensions, and straightness. The mass was taken by using a Mettler AE 240 S/N X207039, and the dimensions were measured by using Trimos Height Gage S/N 0081889 for length, Outside Micrometer S/N M212643 for diameter, and a Poly Micrometer S/N M212649 for thickness. The straightness was measured with a Mitutoyo Indicator S/N M212552.

The eight length measurements every $45^{\circ}$ were taken along each identified perimeter location, as shown in Figure 11(a). Four diameter measurements, as shown in Figure 11(b), were taken at five positions along the length: the first at the top (ID or D1 location), the last at the bottom (perimeter number or D5 location), and three measures in between, as shown in Figure 11(c). Eight thickness measurements were taken at both the top and bottom of each marked perimeter line. The straightness was measured by rotating the specimens and obtaining the deviation from the set reference point. The reference, $\mathrm{P}_{1}-3$, was set by placing the indicator in the center of the tube touching the engraved line " 1 ." The tube ends were held in a stable position as the tubes were rotated. 
(a)
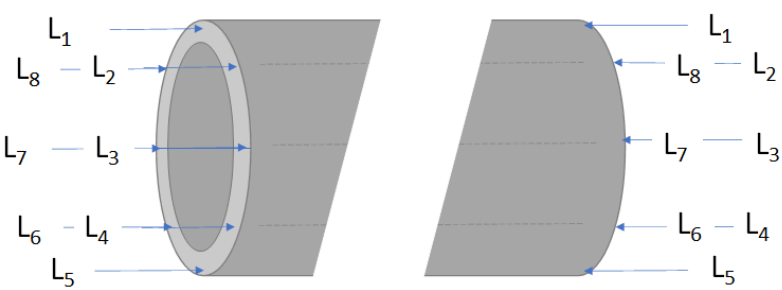

(b)

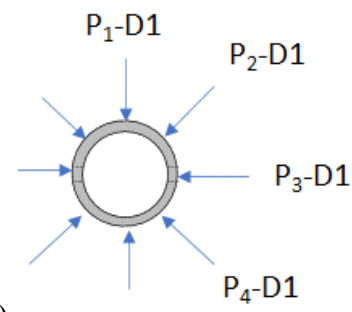

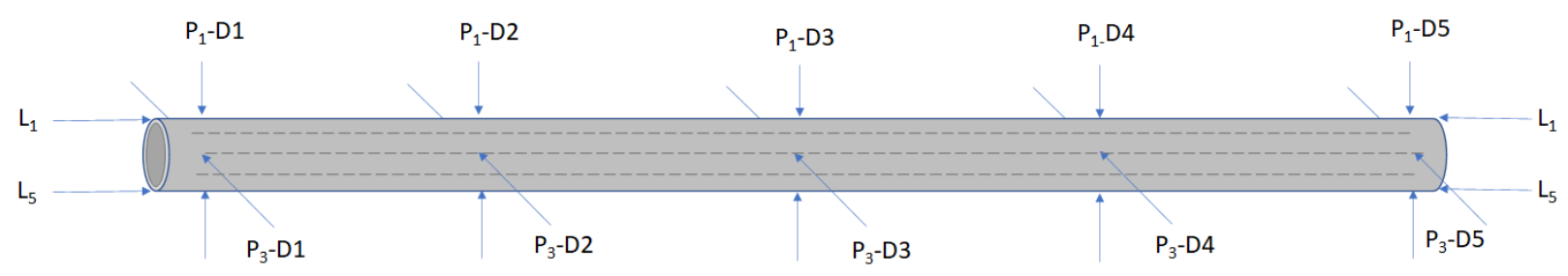

(c)

Figure 11. (a) Dimensional inspection labeling points for length measurements, (b) diameter measurements around the perimeter, and (c) diameter measurements over the span of the length.

\subsection{TRANSLATIONAL STAGE SYSTEM}

A custom 3D, four-directional, remote-controlled translational stage system was assembled to photograph, profile, and strain map the specimens. The system was assembled by using a combination of Thorlabs and Zaber equipment, and the setup is shown in Figure 12.

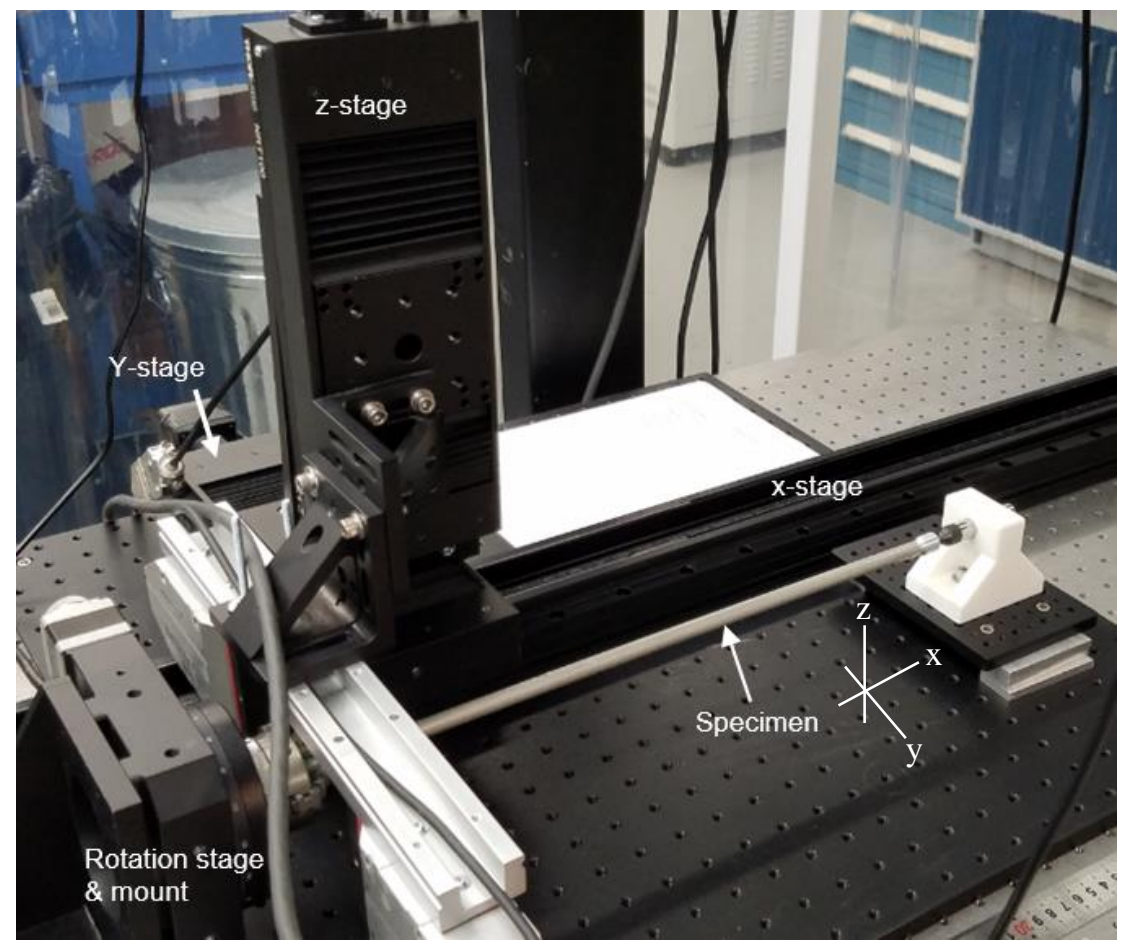

Figure 12. Custom translational stage system setup. 
The Thorlabs manufactured components included the $y$-axis linear stage, the $z$-axis linear stage, and the $360^{\circ} y-z$ rotation stage fixed around the $x$-axis, which were all controlled through a Thorlabs controller supported by Kinesis 32 bit v1.14.24 software. The linear $x$-stage was a Zaber manufactured item that had its own Zaber controller supported by Zaber Console v2.6.7.429 software. The system was operated by one PC. Despite the different manufacturers, all the motorized linear and rotation stages were controlled with incremental movement as low as $0.1 \mu \mathrm{m}$ and $\sim 17.453 \mathrm{mrad}$, respectively. The default moving velocity was set to be $1 \mathrm{~mm} / \mathrm{s}$. Calibration of the stage setup was performed according to the manufacturer's instructions. The $y-z$ linear stages were accurate within $2 \mu \mathrm{m}$ with a repeatability of $1 \mu \mathrm{m}$. The rotational stage has an accuracy of $\pm 820 \mu \mathrm{rad}$ and a bidirectional repeatability of $\pm 350 \mu \mathrm{rad}$. The accuracy of the $x$-linear stage was within $250 \mu \mathrm{m}$ over a $1 \mathrm{~m}$ range with a repeatability of less than $4 \mu \mathrm{m}$.

Two stainless-steel rods with $9.525 \mathrm{~mm}$ diameters and length dimensions similar to the $\mathrm{SiC}-\mathrm{SiC}$ tube specimens $(380 \mathrm{~mm})$ were fabricated with tight tolerances $( \pm 10 \mu \mathrm{m})$ for use as a control specimen. The summary results of these specimen, $\mathrm{AB}$ and $\mathrm{CD}$, are documented in Appendix A.

\subsection{PROFILOMETER INSPECTION}

The profilometry was performed by using a Keyence LS-9030MR 2D optical micrometer that was attached to the linear $y$-arm of the remote-controlled translational stage system, as shown in Figure 13(a). The SiC$\mathrm{SiC}$ tube specimen was installed to rest on tapered end caps attached to the rotation stage and foot mount. The stage and foot mount were vertically aligned as far as possible.

The specimen was positioned so that the engraved line associated with $P_{l}$ was facing up and aligned with the starting position (i.e., $0^{\circ}$ mark) of the rotation stage. Each scan was performed in the axial direction along the length of the specimen, starting at the rotation stage head and ending at the foot mount (i.e., from the end with the engraved perimeter number, $P_{x}$, toward the end with the engraved ID). The micrometer detector is $30 \mathrm{~mm}$ wide, and the tube specimens have a $\sim 9.5 \mathrm{~mm}$ diameter. Thus, each scan recorded the top profile, the bottom profile, and the diameter. After each scan, the specimen was turned $45^{\circ}(0.785 \mathrm{rad})$ to record the profile of each perimeter line.

The profilometer used edge detection to identify the top surface of the specimen and tracked the variation in the profile of this surface as the stage translated along the specimen's length. All profilometry data were postprocessed by using coordinate transformations so that the first and last points - corresponding to the top and bottom of the specimen, respectively-were coplanar, even if the specimen or stage was not perfectly flat.

\subsection{OPTICAL IMAGING USED FOR STRAIN MAPPING}

Included on the linear $y$-arm of the stage system is a mount for a digital microscope that looks down on the top of the specimen. Two digital microscopes, the Dino-Lite AF4115ZT for low magnification $(<50 \times)$ and the Dino-Lite AM73515MT8A for high magnification (>900x), were used to collect digital imagery of the specimens. The low-magnification images were used for panoramic reconstruction to capture unique specimen surface features, and the combination of the high-magnification microscope together with the stage system allowed for the precise determination of the distance between engraved markers.

The high-magnification microscope was used to identify the center of each marker, and the $X, Y$, and $Z$ coordinates together with the rotation angle from the stage system were recorded for each marker. Figure 13 (b) shows the setup. Each marker is about $25 \mathrm{~mm}$ apart along the length of the specimen. For this activity, the specimen was flipped so that the coordinates were recorded, starting at the specimen perimeter number, $P_{x}$ (positioned to rest on the foot mount), moving toward the specimen end with the engraved number 01 or 22 (positioned to rest on the rotation stage). This allowed for better operator visibility and stage control. 
Image analysis can be performed to identify the center of the marker relative to the center of the image more precisely. The displacement measurements are expected to be accurate to within $<10 \mu \mathrm{m}$, which is limited by the image analysis rather than the accuracy of the stage. A $\pm 10 \mu \mathrm{m}$ displacement resolution corresponds to a linear strain resolution of $\pm 0.01 \%$. Image processing was done using Fiji [14].
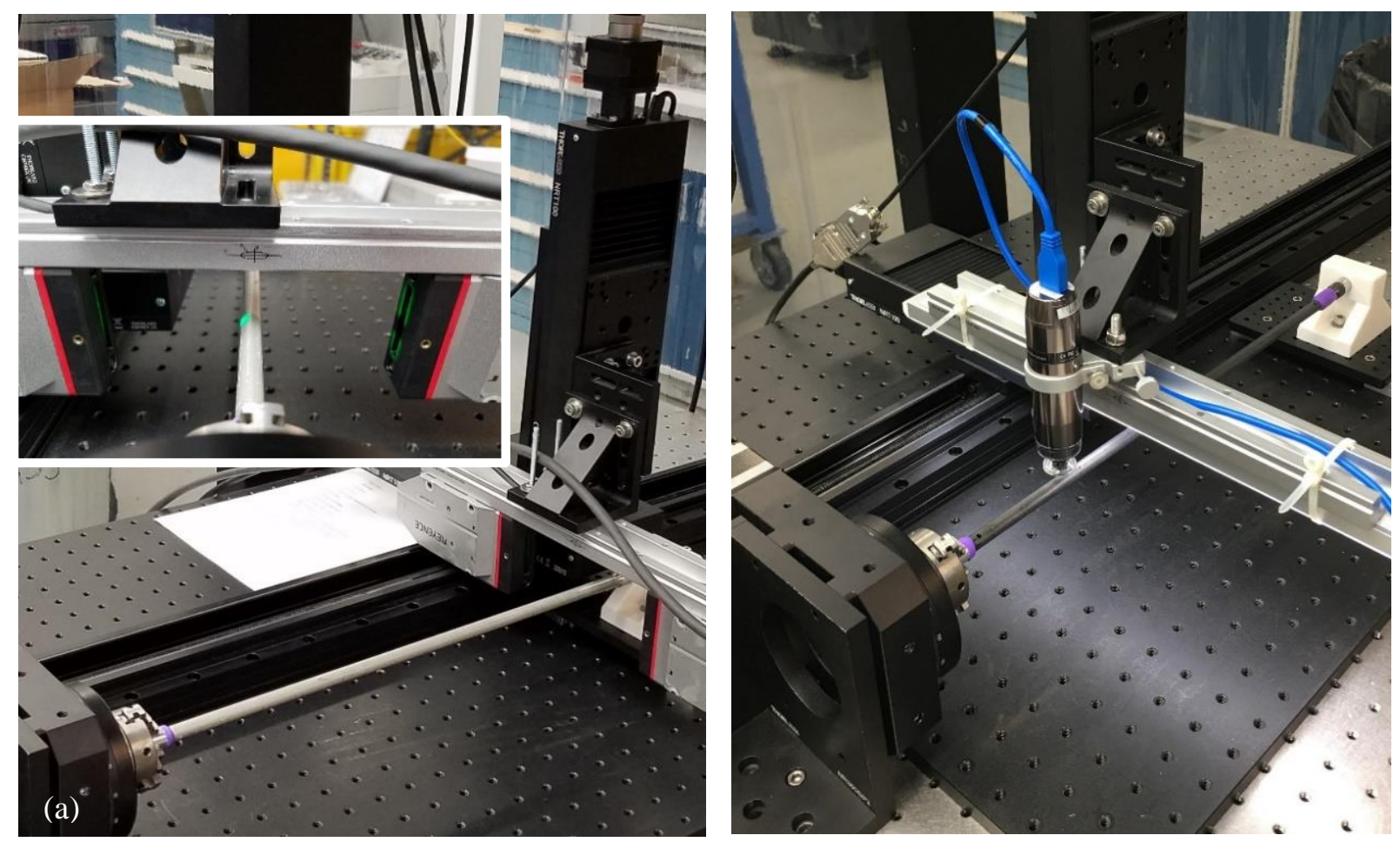

Figure 13. SiC-SiC tube specimen positioned for (a) 2D profile scans with the Keyence Optical Micrometer and (b) local strain measurements using a Dino-Lite high-magnification microscope.

\section{PRE-IRRADIATION CHARACTERIZATION}

\subsection{DIMENSIONAL INSPECTIONS}

The results from dimensional inspections are summarized in Table 1. From dimensional inspections, the results show that both specimens were slightly tapered with a nominal difference of 93 and $121 \mu \mathrm{m}$ from top to bottom for T01 and T22, respectively. The standard deviation of the diameter position $\mathrm{D}_{3}$ is 0.003 $\mathrm{mm}$ for T01 and $0.007 \mathrm{~mm}$ for T22. Also, the thickness between the top and bottom varies between 44 and $83 \mu \mathrm{m}$ on average, respectively. After being cleaned with acetone and ethanol, the masses for T01 and T22 were measured to be 29.800 and 29.497 g, respectively. 
Table 1. Summary of nominal dimensions by dimensional inspection in millimeters on T01 and T22 SiC-SiC tube specimens and control specimen AB.

\begin{tabular}{c|c|c|c|c|c|c|c|c|} 
Specimen & \multicolumn{1}{c}{$\boldsymbol{L}$} & $\boldsymbol{D}_{\boldsymbol{1}}$ & $\boldsymbol{D}_{\boldsymbol{2}}$ & $\boldsymbol{D}_{\boldsymbol{3}}$ & $\boldsymbol{D}_{\boldsymbol{4}}$ & $\boldsymbol{D}_{\boldsymbol{5}}$ & $\boldsymbol{t}_{\text {top }}$ & $\boldsymbol{t}_{\text {bot }}$ \\
\hline \multirow{2}{*}{$\mathrm{T} 01$} & 382.37 & 9.746 & 9.753 & 9.778 & 9.808 & 9.839 & 1.061 & 1.105 \\
\cline { 2 - 9 } $\mathrm{T} 22$ & 382.51 & 9.739 & 9.772 & 9.792 & 9.830 & 9.860 & 1.062 & 1.146 \\
\cline { 2 - 9 }
\end{tabular}

* $L$ is length, $D_{x}$ is diameter at positions $1-5$, and $t_{t o p}$ and $t_{b o t}$ are thickness at top and bottom, respectively.

The straightness results are summarized in Table 2 and show the variation from the reference point, $P_{1^{-}}-3$. The positive values reference the distance above the horizontal zero line in the $z$-direction, and negative values indicate the distance below the horizontal zero line.

Table 2. Straightness measurements of the SiC-SiC tube specimens T01 and T22 in millimeters.

\begin{tabular}{|c|c|c|c|c|c|c|c|c|}
\hline Specimen & $P_{1-3}$ & $P_{2-3}$ & $P_{3}-3$ & $P_{4-3}$ & $P_{5}-3$ & $P_{6-3}$ & $P_{7-3}$ & $\boldsymbol{P}_{8-3}$ \\
\hline T01 & 0.000 & -0.117 & -0.133 & -0.061 & 0.062 & 0.178 & 0.176 & 0.122 \\
\hline $\mathrm{T} 22$ & 0.000 & -0.087 & 0.011 & 0.159 & 0.469 & 0.549 & 0.458 & 0.283 \\
\hline
\end{tabular}

The height difference ( $z$-direction) measured with the aforementioned indicator, shows that the specimens have a slight bow and are not completely straight.

\subsection{PROFILOMETRY INSPECTIONS}

The detailed profile measurements of the SiC-SiC tube specimens T01 and T22 were scanned after calibration, and control scans were performed with a nominally straight stainless-steel bar to ensure that the system did not introduce significant artifacts into the measurements. After scanning the bar in one direction, the bar was reversed and rescanned. The bar was placed directly on the baseplate so that it was independent of the stage system. A maximum deviation of $28 \mu \mathrm{m}$ was observed and caused by the stage and the surface on which the part is sitting. The profile variation of the stainless-steel bar was measured to be 3-4 $\mu \mathrm{m}$ by using a dial indicator. This small variation is much less than the expected radiation-induced bowing (Figure 6) and would likely be present in both pre- and post-irradiation measurements. Thereafter, a stainless-steel rod used as a control specimen positioned in a similar fashion as the SiC-SiC tube specimens was scanned. The results of the control specimen and details of the straight bar are reported in Appendix A.

The top profile, bottom profiles, and diameter of each specimen at every $45^{\circ}$ rotation angle were recorded with each scan. The diameters of both specimens, T01 and T22, were slightly tapered, as shown in Figure 14. This also validates the results of the dimensional inspections. The result from the 2D laser profiler for specimen T01 (Figure 15) are consistent with the indicator inspections, but there is a large inconsistency with specimen T22 (Figure 16) with a $\sim 0.2 \mathrm{~mm}$ difference in the reported straightness. All other dimensions agree with the 2D laser profiler results, so it is more likely an error in the measured indicator results. 


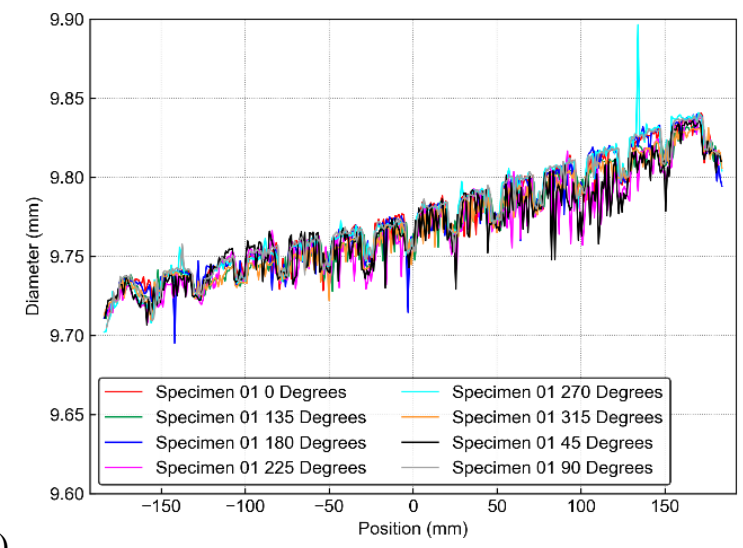

(a)

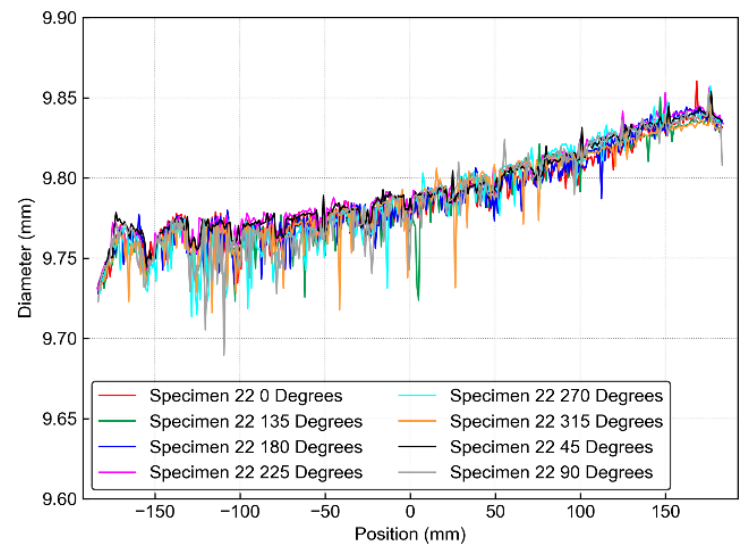

(b)

Figure 14. Diameter plots of the SiC-SiC tube specimens (a) T01 and (b) T22 for the eight respective scans.

Figures 15 and 16 show the respective transform plots of the top and bottom profiles of the tube specimens. The top and bottom profiles shown in the plots correspond to the respective bending profile of the top and bottom outer surface of each specimen at the indicated rotation angle so that the $90^{\circ}$ profile in Figures 15 (a) and 16(a) is equivalent to the inverse profile plot in Figures 15(b) and 16(b), which is shown as the $270^{\circ}$ profile.

(a)

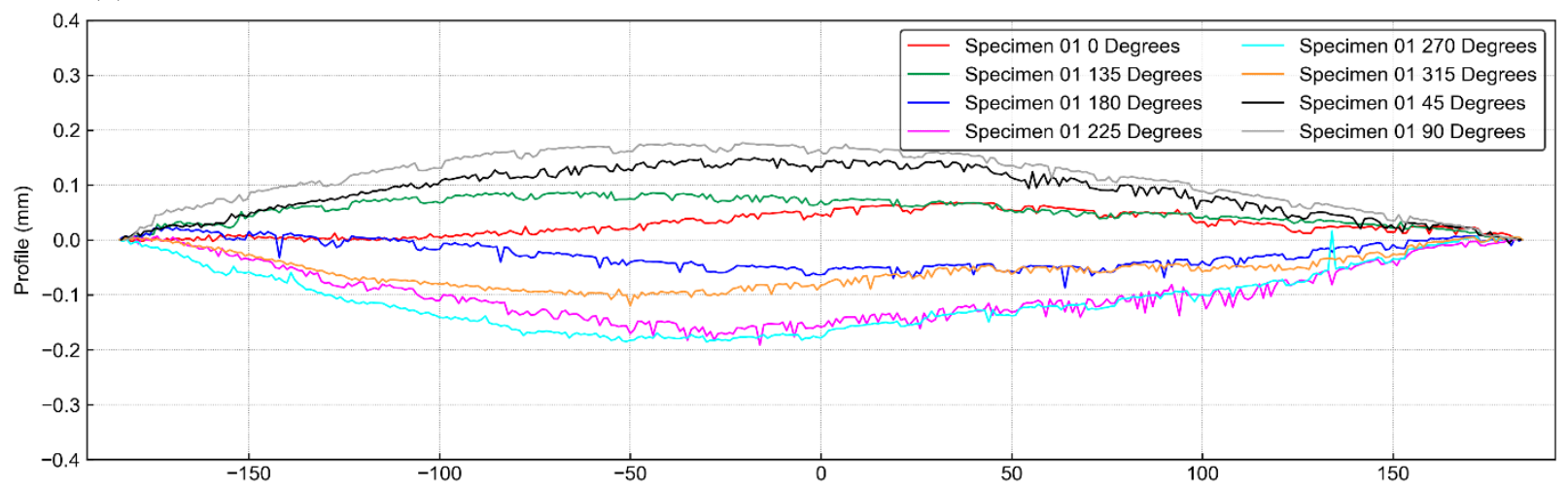

(b) Position (mm)

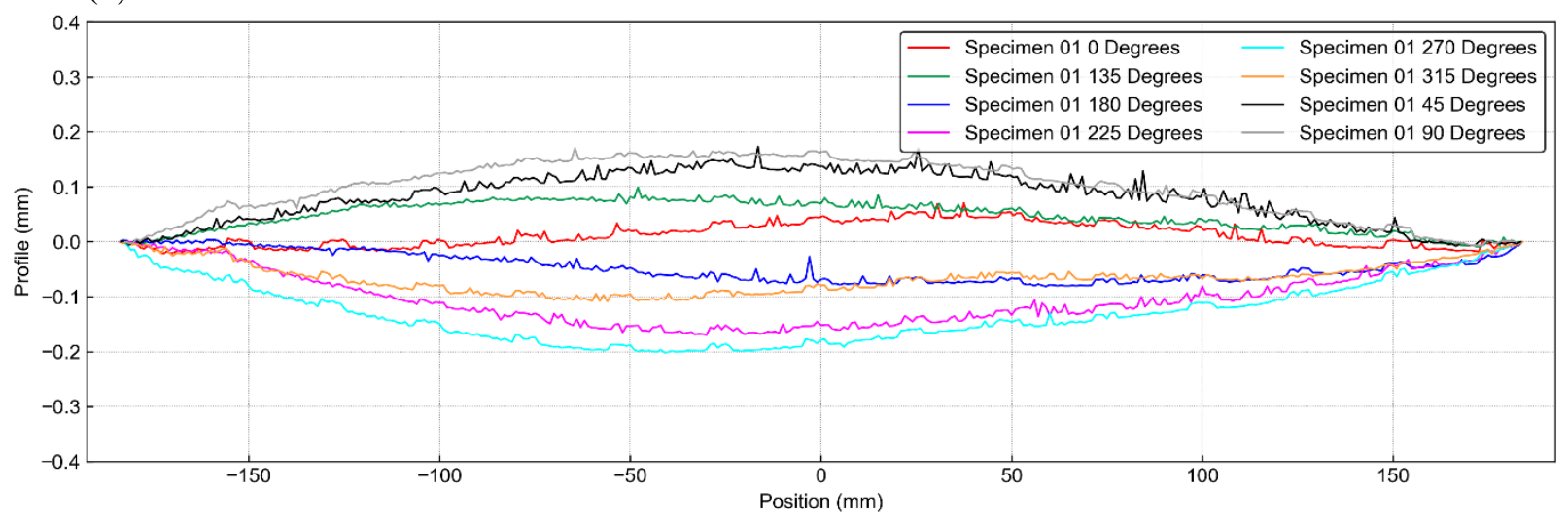

Figure 15. The transformed plot of $\mathrm{SiC}-\mathrm{SiC}$ tube specimen, $\mathrm{T01}$, showing the (a) top profile and (b) corresponding bottom profile of the eight respective scans. 
(a)
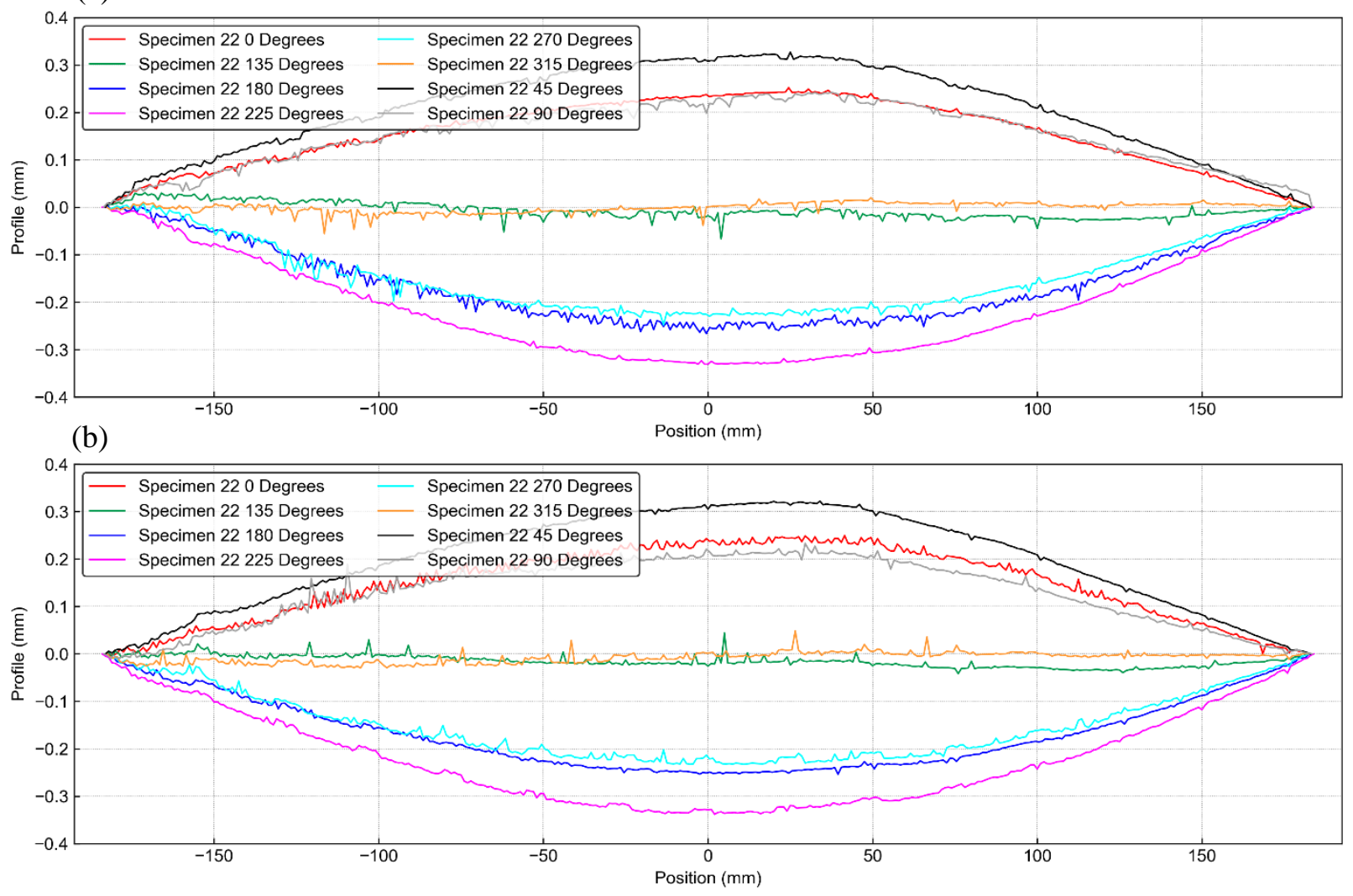

Figure 16. The transformed plot of $\mathrm{SiC}-\mathrm{SiC}$ tube specimen, $\mathrm{T} 22$ showing the (a) top profile and (b) corresponding bottom profile of the eight respective scans.

The position data $Z$ ( $x$-axis) are reversed in these plots so that following the profiles from right to left is equivalent to following the specimen profiles from top to bottom (i.e., from the end marked with the perimeter numbers, $P_{x}$, to the end marked with the specimen ID). This is also equivalent to the vertical installation position during irradiation.

\subsection{FIDUCIAL MARKER RECORDINGS FOR LOCAL STRAIN MAPPING}

Low-magnification images were reconstructed to record closeup views of the specimens, as shown in Figure 17(a). The stage system and the high-magnification microscope were used to locate the center of the fine engraved fiducial marks. Once located, the coordinates were recorded and at each fiducial mark. Several high-magnification images at stepwise height distances from the specimen in $10 \mu \mathrm{m}$ increments (for better focus through depth of field) were taken and then stacked to create the images shown in Figure 17(b). It is possible to detect specific image features smaller than $5 \mu \mathrm{m}$ at a resolution of $\sim 6 \mathrm{px} / \mu \mathrm{m}$ by using image analysis techniques. 

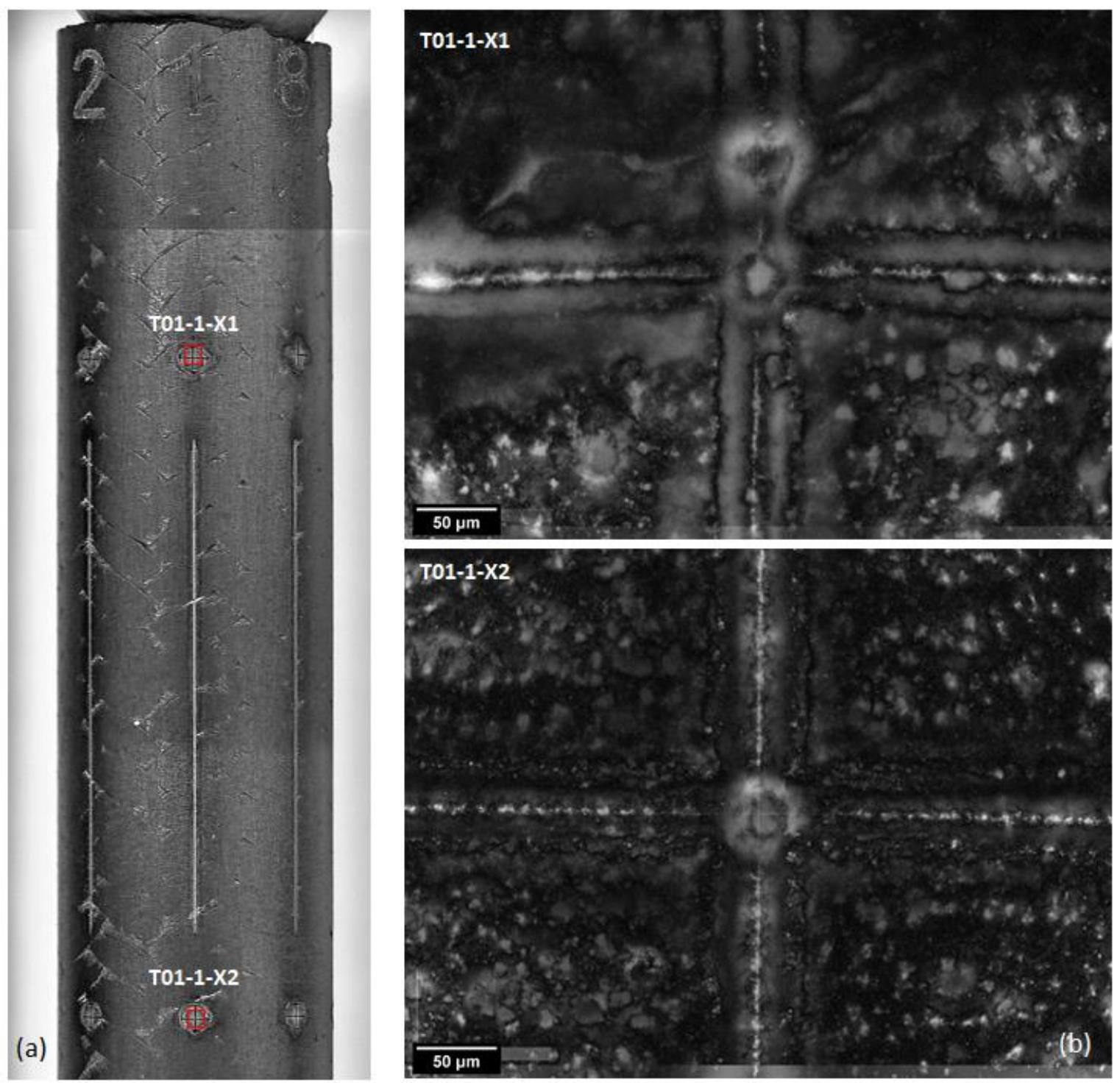

Figure 17. (a) Example of a stitched image section of specimen T01 showing the (b) stacked images created of the engraved fiducial markings T01-1-X1 and T01-1-X2.

Figure 18 shows the respective maps of the recorded coordinates of the engraved fiducial markings on every $45^{\circ}$ rotational angle of specimen T01 and T22. The first fiducial mark closest to the engraved perimeter number, $P_{x}$, is used as the reference or starting point for the specific series. As the specimen was flipped, the $P_{x}$ recordings were associated with a counterclockwise rotation angle of the rotation stage, and although the specimen was $\sim 382 \mathrm{~mm}$ long, the total distance from the first marker to the last (along the length) was $\sim 355 \mathrm{~mm}$. The exact coordinate details are shown in Appendix B.

In each case, there was a slight drift during the fine engraving procedure because the markers were slightly skewed, deviating in the $y$-direction as the distance away from the starting position increase.

One marker of specimen $\mathrm{T} 01$ in the $\mathrm{P}_{4}$ series was incorrectly recorded. Upon closer investigation, it was observed that the $z$ - and $y$-coordinates were switched during the recording. The correction is reflected in the plot, but the specific marker was highlighted. 

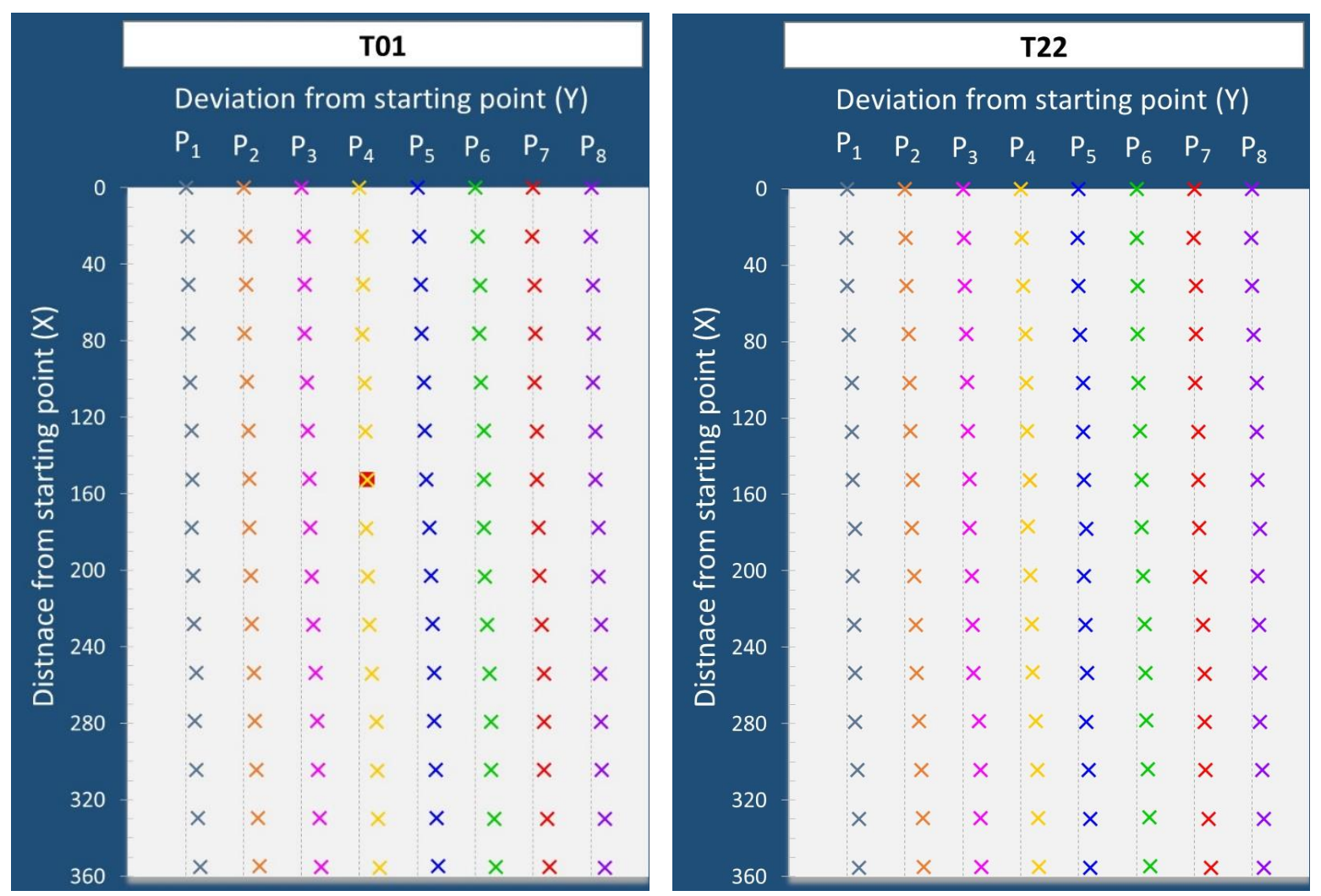

Figure 18. The recorded pre-irradiation fiducial marker plots for specimen T01 (left) and T22 (right) showing markers respective with the associated perimeter number's starting point. Units in millimeters.

\section{CONCLUSION}

This report summarizes the purpose, experiment design, specimen preparation, and pre-irradiation characterization techniques prepared and applied for the two SiC-SiC clad tube specimens. Both specimens were inspected and characterized before being assembled as part of the channel box bowing experiment for HFIR irradiation.

The dimensional inspection results mostly correspond to the profilometry results with both demonstrating that the two $\mathrm{SiC}-\mathrm{SiC}$ tube specimens are not completely straight and are slightly tapered in diameter. Specimen $\mathrm{T} 01$ has the largest measured bow at the $270^{\circ}$ rotational angle - which corresponds to the inverse $90^{\circ}$ rotational angle - with a nominal value of $0.2 \mathrm{~mm}$, and T22 has the largest measured bow at the $225^{\circ}$ rotational angle - which corresponds to the inverse $45^{\circ}$ rotational angle - with a nominal value of $0.35 \mathrm{~mm}$.

The fine engraved fiducial markers were individually measured with respect to the specified reference points by locating the center of the cross marking with the high-magnification images and taking the respective coordinates provided by the stage system.

The experiment completed two HFIR cycle irradiations: cycles 492 and 493. With a two-cycle irradiation, the bow caused by irradiation is anticipated to be $0.8-1.0 \mathrm{~mm}$ for the two specimens, depending on the irradiation position (i.e., closer or further from the core). 


\section{REFERENCES}

[1] Katoh, Y., et al., "Continuous $\mathrm{SiC}$ fiber, CVI SiC matrix composites for nuclear applications: Properties and irradiation effects". J. Nucl. Mater., 448 (2014) p. 448-476.

[2] Singh, G., et al., "Parametric Evaluation of SiC/SiC Composite Cladding with UO2 Fuel for LWR Applications: Fuel Rod Interactions and Impact of Nonuniform Power Profile in Fuel Rod". J. Nucl. Mater., 499 (2018) p. 155-167.

[3] Christian M. Petrie, Josina W. Geringer, Adam James, Kurt Smith, Joseph R. Burns, Annabelle G. Le Coq, Nicholas Russell, Christian P. Deck, Takaaki Koyanagi, Yutai Katoh, "HFIR SiC Bowing Test Ready to Insert”, ORNL Report, ORNL/SPR-2021/1838.

[4] Y. Lee, M.S. Kazimi, "A structural model for multi-layered ceramic cylinders and its application to silicon carbide cladding of light water reactor fuel", J. Nucl. Mater. 458 (2015) p. 87-105.

[5] G.A. Newsome, L.L. Snead, T. Hinoki, Y. Katoh, D. Peters, J. Nucl. Mater. 371 (2007) 76-89.

[6] K. Ozawa, Y. Katoh, L.L. Snead, T. Nozawa, T. Hinoki, A. Hasegawa, The effects of neutron irradiation on dimensional change in advanced silicon carbide composites, DOE/ER-0313/46 Fusion Reactor Materials Semiannual Progress Report for Period Ending June 30, 2009, pp. 4-15.

[7] Y. Katoh, K. Ozawa, S. Shih, T. Nozawa, R. Shinavski, A. Hasegawa, L. Snead, Continuous SiC fiber, CVI SiC matrix composites for nuclear applications: Properties and irradiation effects, Journal of Nucl. Mater. 448 (2014) p. 448-476.

[8] Yutai Katoh, Takashi Nozawa, Chunghao Shih, Kazumi Ozawa, Takaaki Koyanagi, Wally Porter, Lance L. Snead, High-dose neutron irradiation of Hi-Nicalon Type S silicon carbide composites. Part 2: Mechanical and physical properties, J. Nucl. Mater. 462 (2015) p. 450-457.

[9] Y. Katoh, L. Snead, S. Golubov, E. Lara-Curzio, Analyzing irradiation-induced creep of silicon carbide, in: Mechanical Properties and Performance of Engineering Ceramics and Composites III, Wiley, 2007.

[10] Yutai Katoh, Takaaki Koyanagi, Joel L. McDuffee, Lance L. Snead, Ken Yueh, Dimensional stability and anisotropy of $\mathrm{SiC}$ and $\mathrm{SiC}$-based composites in transition swelling regime, J. Nucl. Mater. 499 (2018) p. 471-479.

[11] C.M. Petrie, J. McDuffee, N. Cetiner, R. Howard, P. Mulligan, "Nuclear Science User Facilities Irradiation Capabilities at Oak Ridge National Laboratory," Transactions of the American Nuclear Society Vol. 116 (2017) p.377-380.

[12] Christian M. Petrie, Kurt R. Smith, Joseph R. Burns, Annabelle G. Le Coq, Yutai Katoh, Christian P. Deck, "Irradiation Testing of a $\mathrm{SiC} / \mathrm{SiC}$ Channel Box in the High Flux Isotope Reactor", Oak Ridge National Laboratory, ORNL/TM-2018/957.

[13] C.M. Petrie, J. Burns, C. Deck, Y. Katoh, "Bowing analysis of a SiC/SiC channel box irradiation experiment in the HFIR", ICACC 2019, Daytona Beach, FL, January 2019.

[14] Schindelin, J., Arganda-Carreras, I., Frise, E., Kaynig, V., Longair, M., Pietzsch, T., ... Cardona, A. (2012). Fiji: an open-source platform for biological-image analysis. Nature Methods, 9(7), 676682. doi:10.1038/nmeth.2019 


\section{APPENDIX A. INSPECTION RESULTS OF THE STEEL CONTROL SPECIMEN}




$$
\text { A-2 }
$$




\section{APPENDIX A. INSPECTION RESULTS OF THE STAINLESS-STEEL CONTROL SPECIMEN}

Tight-tolerance $( \pm 10 \mu \mathrm{m})$, multipurpose 304 stainless-steel rods with a $9.525 \mathrm{~mm}$ diameter and length dimensions cut to the size of the $\mathrm{SiC}-\mathrm{SiC}$ tube specimens $(380 \mathrm{~mm}$ ) were used for control specimens.

The purpose of the control specimens is to validate system performance because the custom 3D translation system will be disassembled. A similar system will be assembled elsewhere to perform post-irradiation evaluation. The system performance will then be validated via control specimens.

Two control specimens, $\mathrm{AB}$ and $\mathrm{CD}$, were inspected by applying similar methods, as described in the report. They were not engraved in the same way so that the surfaces remained undisturbed. The ends were slightly tapered to snugly fit the mounting fixtures and marked as shown in Figure A.1.

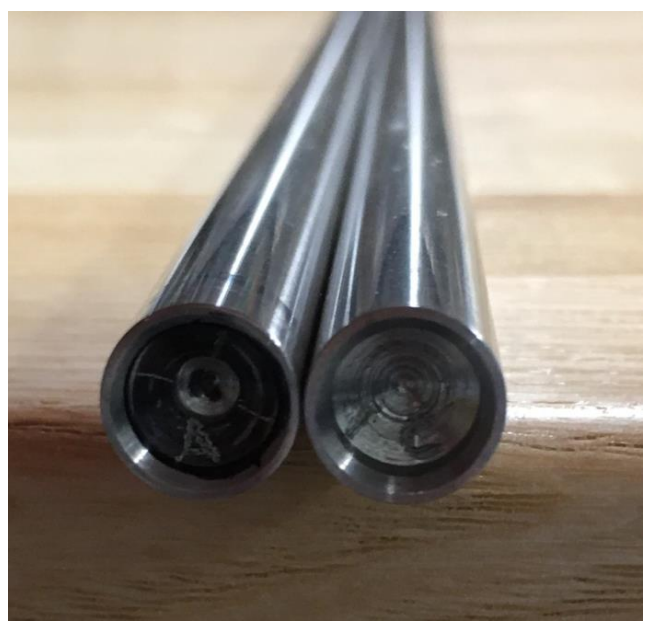

Figure A.1. Control specimen $\mathrm{AB}$ and $\mathrm{CD}$ with marker lines.

The diameter, cylindricity, and straightness of the respective rods were measured. As with the composite specimens, the straightness was measured at the center of the rod every $45^{\circ}$ for positions $1-8$. The rods were marked with a red line using a permanent marker to indicate the position where it was measured.

The diameter is consistent throughout the specimen length. This was also confirmed with the profiler scans, which measured the diameter of control specimen, $\mathrm{AB}$, as $9.518 \mathrm{~mm}$ with a standard deviation of $4.7 \times 10^{-}$ ${ }^{4}$ and control specimen, $\mathrm{CD}$, as $9.533 \mathrm{~mm}$ with a standard deviation of $6.4 \times 10^{-4}$. Both control specimens $\mathrm{AB}$ and $\mathrm{CD}$ are not perfectly straight and were measured with a maximum deviation of $28 \mu \mathrm{m}$ for both. The inspection report is shown in Figure A.2. 


\begin{tabular}{|c|c|c|c|}
\hline$Q C \#^{*}$ & Inspection Result & Drawing Requirement & Inspection Method \\
\hline & & $A-B$ & \\
\hline A-END & $9.522 \mathrm{~mm}$ & DIAMETER & OUTSIDE MICROMETER \\
\hline MIDDLE & $9.522 \mathrm{~mm}$ & DIAMETER & OUTSIDE MICROMETER \\
\hline \multirow[t]{2}{*}{ B-END } & $9.523 \mathrm{~mm}$ & DIAMETER & OUTSIDE MICROMETER \\
\hline & $0.031 \mathrm{~mm}$ & CYLINDRICITY & MITUTOYO RA2200AH \\
\hline $\begin{array}{c}\text { Position } 1 \\
\text { (RED DOT UP) }\end{array}$ & 0 & STRAIGHTNESS & HEIGHT GAGE \\
\hline Position 2 & -0.006 & STRAIGHTNESS & HEIGHT GAGE \\
\hline Position 3 & -0.007 & STRAIGHTNESS & HEIGHT GAGE \\
\hline Position 4 & 0.003 & STRAIGHTNESS & HEIGHT GAGE \\
\hline Position 5 & 0.021 & STRAIGHTNESS & HEIGHT GAGE \\
\hline Position 6 & 0.028 & STRAIGHTNESS & HEIGHT GAGE \\
\hline Position 7 & 0.022 & STRAIGHTNESS & HEIGHT GAGE \\
\hline \multirow[t]{2}{*}{ Position 8} & 0.014 & STRAIGHTNESS & HEIGHT GAGE \\
\hline & & C-D & \\
\hline C-END & $9.522 \mathrm{~mm}$ & DIAMETER & OUTSIDE MICROMETER \\
\hline MIDDLE & $9.523 \mathrm{~mm}$ & DIAMETER & OUTSIDE MICROMETER \\
\hline \multirow[t]{2}{*}{ D-END } & $9.522 \mathrm{~mm}$ & DIAMETER & OUTSIDE MICROMETER \\
\hline & $0.031 \mathrm{~mm}$ & CYLINDRICITY & MITUTOYO RA2200AH \\
\hline $\begin{array}{c}\text { Position } 1 \\
\text { (RED DOT UP) }\end{array}$ & 0 & STRAIGHTNESS & HEIGHT GAGE \\
\hline Position 2 & -0.010 & STRAIGHTNESS & HEIGHT GAGE \\
\hline Position 3 & -0.011 & STRAIGHTNESS & HEIGHT GAGE \\
\hline Position 4 & -0.003 & STRAIGHTNESS & HEIGHT GAGE \\
\hline Position 5 & 0.018 & STRAIGHTNESS & HEIGHT GAGE \\
\hline Position 6 & 0.028 & STRAIGHTNESS & HEIGHT GAGE \\
\hline Position 7 & 0.027 & STRAIGHTNESS & HEIGHT GAGE \\
\hline Position 8 & 0.017 & STRAIGHTNESS & HEIGHT GAGE \\
\hline \multicolumn{4}{|c|}{ The cylindricity measurement was taken at 5 places along the length of the part. } \\
\hline
\end{tabular}

Figure A.2. Metrology inspection report of control specimens AB and CD.

Figures A.3 and A.4 show the transformed profiles of control specimens AB and CD, respectively. The profiles were force-fitted through zero at the ends. The top and bottom profiles are the top and bottom profile scans while the specimen was positioned at a specific rotational angle, as listed in the graphs. 


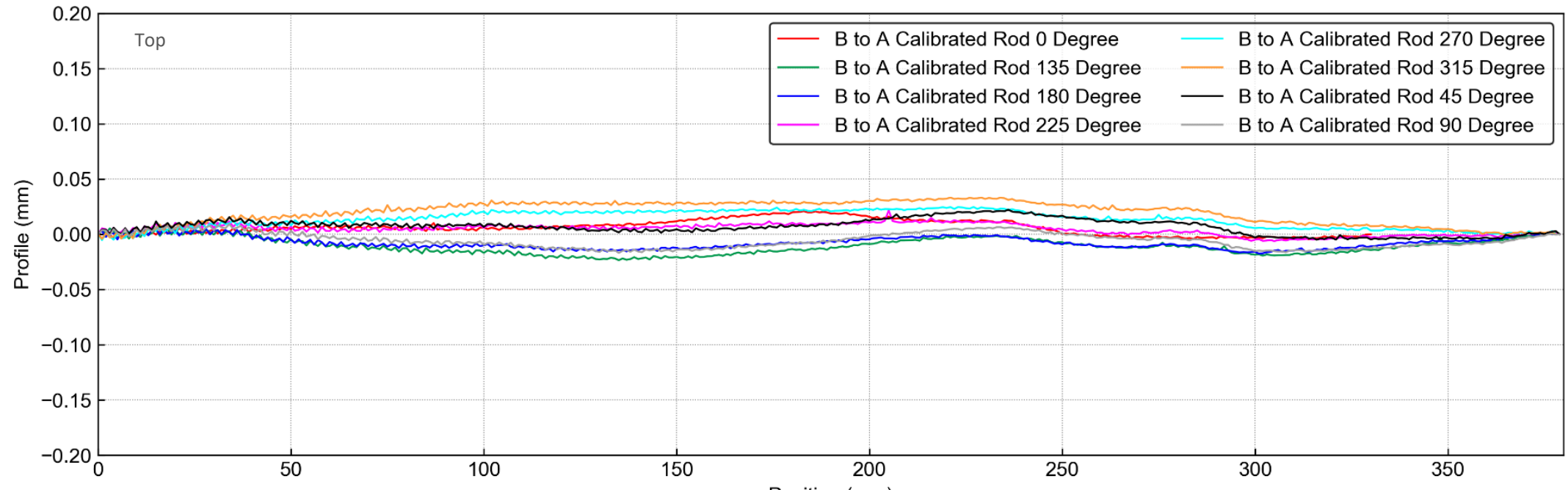

Position (mm)

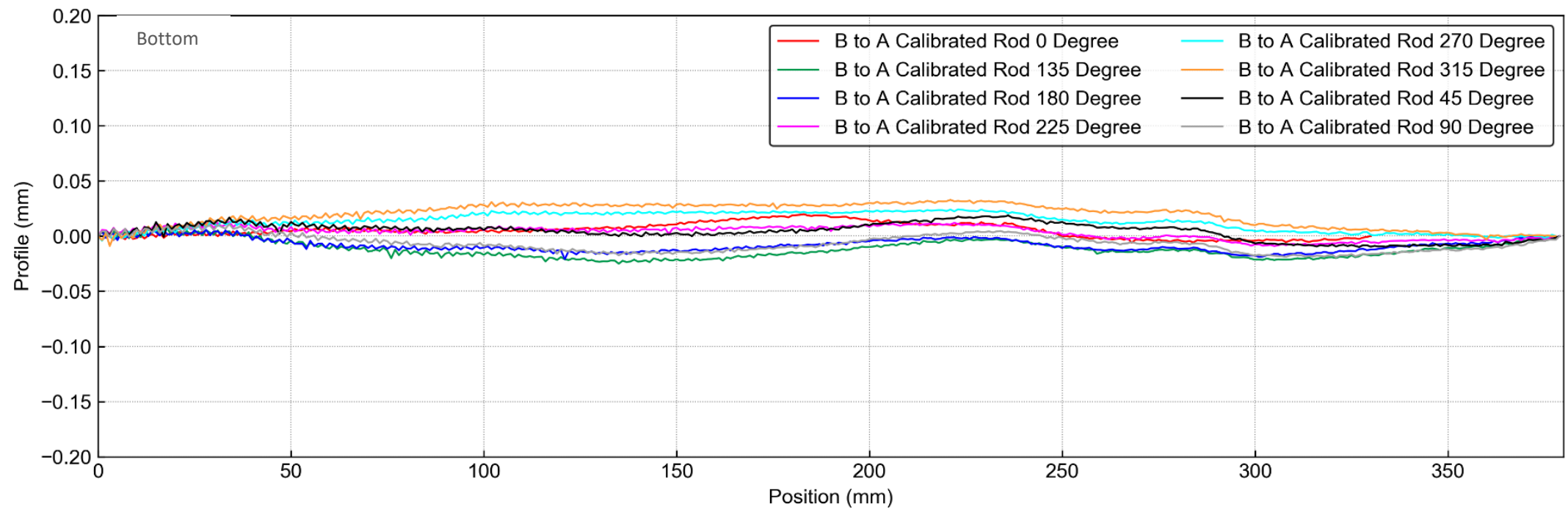

Figure A.3. Transformed profile results (top and bottom) of control rod specimen AB. 

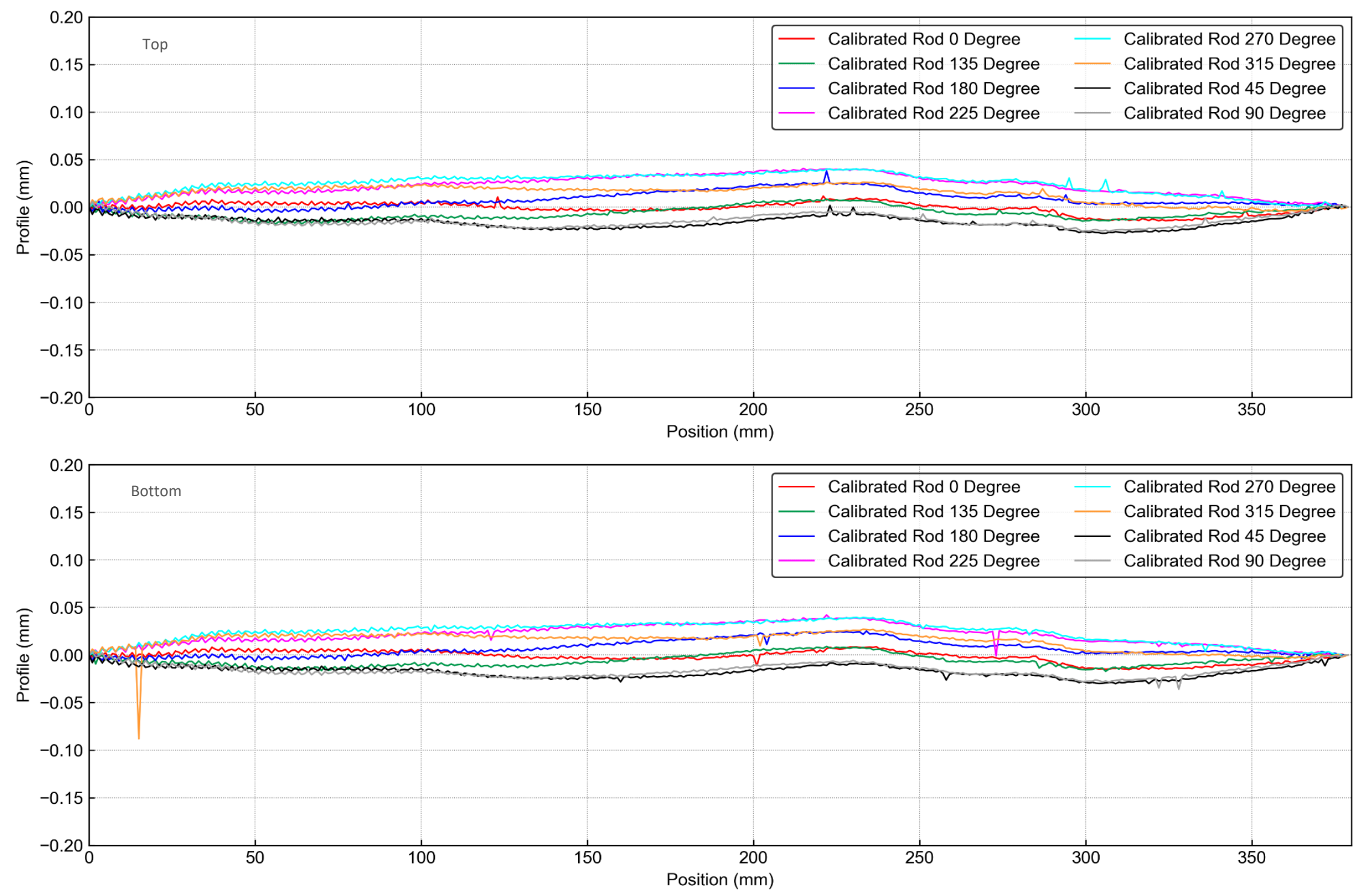

Figure A.4. Transformed profile results (top and bottom) of control rod specimen CD. 
Both figures show that all the datasets indicate a gradual increase and a peak near the $225 \mathrm{~mm}$ position on the scale. This indicates an artifact, suggesting that the detector's track is not perfectly straight. This was confirmed by using a straight stainless-steel bar that was scanned in one direction and then flipped so that it was rescanned in the reversed direction. Figure A.5 shows the results of the forward scan and reversed scan, which indicates that some small artifact creates a $\sim 25-28 \mu \mathrm{m}$ deviation. The stainless-steel bar was independently measured to have a straightness of 3-4 $\mu \mathrm{m}$. This explains the very large profile variation between the indicator-measured straightness and those measured by the 2D laser profiler.

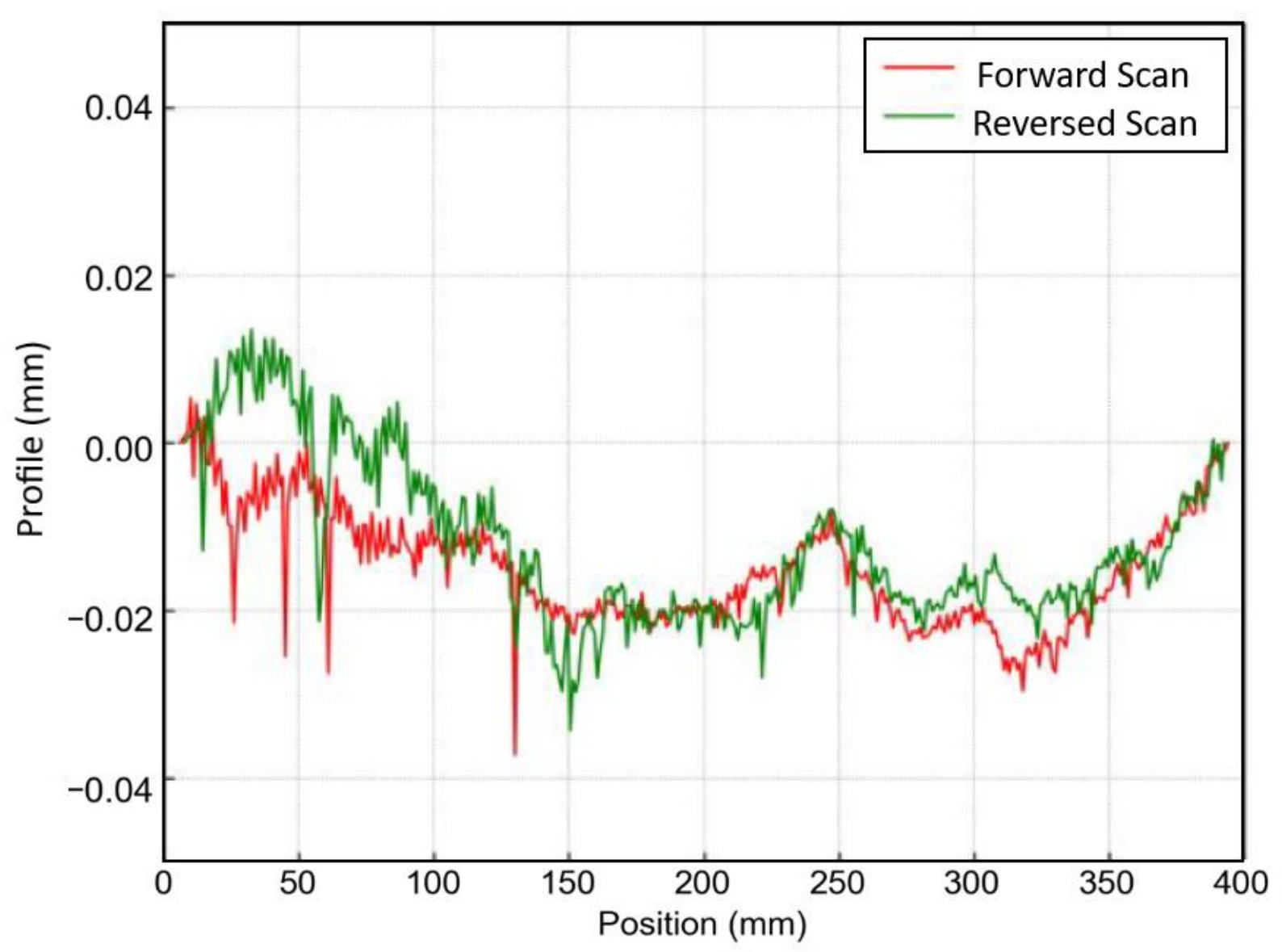

Figure A.5. Forward and reverse scan of a straight bar. 

APPENDIX B. MEASURED LOCATIONS OF ENGRAVED MARKERS OF THE SIC-SIC TUBE SPECIMENS 
B-2 


\section{APPENDIX B. MEASURED LOCATIONS OF ENGRAVED MARKERS OF THE SIC-SIC TUBE SPECIMENS}

Tables B.1-B.16 show the measured coordinates as retrieved from the translational stage system. For postirradiation comparison, the marker IDs are labeled with the axial direction $(z)$ of the irradiation experiment as it was inserted into HFIR. In each case, the marker "-X1" is the reference closest to the end that is aligned with the top of the reactor, and "-X15" is closest to the end that is aligned with the bottom of the reactor.

Table B.1. Specimen T01, perimeter face $P_{1}$ rotational angle: $0.012^{\circ}$.

\begin{tabular}{|l|c|c|c|}
\hline Marker ID & $\begin{array}{c}\text { Axial } \\
\text { direction } \\
\text { of the tube } \\
(\mathbf{m m}) \\
{[\mathbf{x}]}\end{array}$ & $\begin{array}{c}\text { Variable } \\
\text { distance } \\
\text { from ref. } \\
(\mathbf{m m}) \\
{[\mathbf{y}]}\end{array}$ & $\begin{array}{c}\text { Surface } \\
\text { normal } \\
\text { distance } \\
(\mathbf{m m}) \\
{[\mathbf{z}]}\end{array}$ \\
\hline T01-1-X1 & 261.302 & 92.660 & 89.470 \\
\hline T01-1-X2 & 286.738 & 92.499 & 89.460 \\
\hline T01-1-X3 & 311.989 & 92.419 & 89.450 \\
\hline T01-1-X4 & 337.622 & 92.439 & 89.430 \\
\hline T01-1-X5 & 363.056 & 92.266 & 89.410 \\
\hline T01-1-X6 & 388.313 & 92.170 & 89.390 \\
\hline T01-1-X7 & 413.654 & 92.060 & 89.380 \\
\hline T01-1-X8 & 438.880 & 92.120 & 89.340 \\
\hline T01-1-X9 & 464.226 & 92.019 & 89.300 \\
\hline T01-1-X10 & 489.485 & 91.927 & 89.260 \\
\hline T01-1-X11 & 514.918 & 91.755 & 89.220 \\
\hline T01-1-X12 & 540.220 & 91.871 & 89.200 \\
\hline T01-1-X13 & 565.554 & 91.721 & 89.170 \\
\hline T01-1-X14 & 590.807 & 91.590 & 89.160 \\
\hline T01-1-X15 & 616.247 & 91.386 & 89.140 \\
\hline
\end{tabular}

Table B.2. Specimen T01, perimeter face $P_{2}$, rotational angle: $315.017^{\circ}$.

\begin{tabular}{|l|c|c|c|}
\hline Marker ID & $\begin{array}{c}\text { Axial } \\
\text { direction } \\
\text { of the tube } \\
(\mathbf{m m}) \\
{[\mathbf{x}]}\end{array}$ & $\begin{array}{c}\text { Variable } \\
\text { distance } \\
\text { from ref. } \\
(\mathbf{m m}) \\
{[\mathbf{y}]}\end{array}$ & $\begin{array}{c}\text { Surface } \\
\text { normal } \\
\text { distance } \\
(\mathbf{m m}) \\
{[\mathbf{z}]}\end{array}$ \\
\hline T01-2-X1 & 261.431 & 92.660 & 89.470 \\
\hline T01-2-X2 & 286.857 & 92.501 & 89.460 \\
\hline T01-2-X3 & 312.016 & 92.430 & 89.460 \\
\hline T01-2-X4 & 337.498 & 92.577 & 89.480 \\
\hline T01-2-X5 & 362.952 & 92.377 & 89.430 \\
\hline T01-2-X6 & 388.204 & 92.272 & 89.420 \\
\hline T01-2-X7 & 413.555 & 92.156 & 89.440 \\
\hline T01-2-X8 & 438.999 & 92.194 & 89.380 \\
\hline T01-2-X9 & 464.353 & 92.060 & 89.350 \\
\hline T01-2-X10 & 489.614 & 91.958 & 89.300 \\
\hline T01-2-X11 & 515.050 & 91.771 & 89.240 \\
\hline T01-2-X12 & 540.285 & 91.682 & 89.200 \\
\hline T01-2-X13 & 565.622 & 91.556 & 89.150 \\
\hline T01-2-X14 & 590.869 & 91.445 & 89.090 \\
\hline T01-2-X15 & 616.304 & 91.266 & 89.030 \\
\hline
\end{tabular}


Table B.3. Specimen T01, perimeter face $P_{3}$ rotational angle: $271.088^{\circ}$.

\begin{tabular}{|l|c|c|c|}
\hline Marker ID & $\begin{array}{c}\text { Axial } \\
\text { direction } \\
\text { of the tube } \\
\mathbf{( m m} \\
{[\mathbf{x}]}\end{array}$ & $\begin{array}{c}\text { Variable } \\
\text { distance } \\
\text { from ref. } \\
\mathbf{( m m}) \\
{[\mathbf{y}]}\end{array}$ & $\begin{array}{c}\text { Surface } \\
\text { normal } \\
\text { distance } \\
\mathbf{( m m} \\
{[\mathbf{z}]}\end{array}$ \\
\hline T01-3-X1 & 261.296 & 92.660 & 89.540 \\
\hline T01-3-X2 & 286.727 & 92.487 & 89.540 \\
\hline T01-3-X3 & 311.980 & 92.396 & 89.530 \\
\hline T01-3-X4 & 337.529 & 92.373 & 89.520 \\
\hline T01-3-X5 & 362.963 & 92.200 & 89.500 \\
\hline T01-3-X6 & 388.223 & 92.101 & 89.490 \\
\hline T01-3-X7 & 413.564 & 91.991 & 89.480 \\
\hline T01-3-X8 & 439.041 & 91.922 & 89.460 \\
\hline T01-3-X9 & 464.387 & 91.790 & 89.420 \\
\hline T01-3-X10 & 489.646 & 91.668 & 89.360 \\
\hline T01-3-X11 & 515.085 & 91.471 & 89.320 \\
\hline T01-3-X12 & 540.206 & 91.328 & 89.280 \\
\hline T01-3-X13 & 565.546 & 91.211 & 89.220 \\
\hline T01-3-X14 & 590.802 & 91.108 & 89.150 \\
\hline T01-3-X15 & 616.236 & 90.936 & 89.090 \\
\hline
\end{tabular}

Table B.5. Specimen T01, perimeter face $P_{5}$ rotational angle: $182.631^{\circ}$.

\begin{tabular}{|l|c|c|c|}
\hline Marker ID & $\begin{array}{c}\text { Axial } \\
\text { direction } \\
\text { of the tube } \\
(\mathbf{m m}) \\
{[\mathbf{x}]}\end{array}$ & $\begin{array}{c}\text { Variable } \\
\text { distance } \\
\text { from ref. } \\
(\mathbf{m m}) \\
{[\mathbf{y}]}\end{array}$ & $\begin{array}{c}\text { Surface } \\
\text { normal } \\
\text { distance } \\
(\mathbf{m m}) \\
{[\mathbf{z}]}\end{array}$ \\
\hline T01-5-X1 & 261.318 & 92.660 & 89.680 \\
\hline T01-5-X2 & 286.757 & 92.482 & 89.630 \\
\hline T01-5-X3 & 312.007 & 92.387 & 89.590 \\
\hline T01-5-X4 & 337.604 & 92.271 & 89.550 \\
\hline T01-5-X5 & 363.044 & 92.098 & 89.510 \\
\hline T01-5-X6 & 388.302 & 92.007 & 89.480 \\
\hline T01-5-X7 & 413.636 & 91.898 & 89.460 \\
\hline T01-5-X8 & 438.895 & 91.592 & 89.440 \\
\hline T01-5-X9 & 464.237 & 91.472 & 89.420 \\
\hline T01-5-X10 & 489.497 & 91.367 & 89.410 \\
\hline T01-5-X11 & 514.939 & 91.183 & 89.380 \\
\hline T01-5-X12 & 540.173 & 91.193 & 89.360 \\
\hline T01-5-X13 & 565.502 & 91.097 & 89.350 \\
\hline T01-5-X14 & 590.754 & 91.019 & 89.330 \\
\hline T01-5-X15 & 616.194 & 90.866 & 89.350 \\
\hline
\end{tabular}

Table B.4. Specimen T01, perimeter face $P_{4}$ rotational angle: $224.485^{\circ}$.

\begin{tabular}{|l|c|c|c|}
\hline Marker ID & $\begin{array}{c}\text { Axial } \\
\text { direction } \\
\text { of the tube } \\
(\mathbf{m m}) \\
{[\mathbf{x}]}\end{array}$ & $\begin{array}{c}\text { Variable } \\
\text { distance } \\
\text { from ref. } \\
(\mathbf{m m}) \\
{[\mathbf{y}]}\end{array}$ & $\begin{array}{c}\text { Surface } \\
\text { normal } \\
\text { distance } \\
(\mathbf{m m}) \\
{[\mathbf{z}]}\end{array}$ \\
\hline T01-4-X1 & 260.979 & 92.660 & 89.620 \\
\hline T01-4-X2 & 286.410 & 92.479 & 89.610 \\
\hline T01-4-X3 & 311.667 & 92.382 & 89.590 \\
\hline T01-4-X4 & 337.660 & 92.392 & 89.590 \\
\hline T01-4-X5 & 363.096 & 92.214 & 89.530 \\
\hline T01-4-X6 & 388.356 & 92.120 & 89.490 \\
\hline T01-4-X7 & 413.692 & 92.013 & 89.470 \\
\hline T01-4-X8 & 438.979 & 92.062 & 89.450 \\
\hline T01-4-X9 & 464.324 & 91.932 & 89.420 \\
\hline T01-4-X10 & 489.585 & 91.814 & 89.380 \\
\hline T01-4-X11 & 515.021 & 91.616 & 89.340 \\
\hline T01-4-X12 & 540.286 & 91.221 & 89.320 \\
\hline T01-4-X13 & 565.622 & 91.130 & 89.290 \\
\hline T01-4-X14 & 590.876 & 91.049 & 89.230 \\
\hline T01-4-X15 & 616.309 & 90.897 & 89.200 \\
\hline
\end{tabular}

Table B.6. Specimen T01, perimeter face $P_{6}$ rotational angle: $134.161^{\circ}$.

\begin{tabular}{|l|c|c|c|}
\hline Marker ID & $\begin{array}{c}\text { Axial } \\
\text { direction } \\
\text { of the tube } \\
(\mathbf{m m}) \\
{[\mathbf{x}]}\end{array}$ & $\begin{array}{c}\text { Variable } \\
\text { distance } \\
\text { from ref. } \\
(\mathbf{m m}) \\
{[\mathbf{y}]}\end{array}$ & $\begin{array}{c}\text { Surface } \\
\text { normal } \\
\text { distance } \\
(\mathbf{m m}) \\
{[\mathbf{z}]}\end{array}$ \\
\hline T01-6-X1 & 261.115 & 92.660 & 89.760 \\
\hline T01-6-X2 & 286.549 & 92.486 & 89.720 \\
\hline T01-6-X3 & 311.933 & 92.263 & 89.670 \\
\hline T01-6-X4 & 337.270 & 92.348 & 89.620 \\
\hline T01-6-X5 & 362.708 & 92.173 & 89.580 \\
\hline T01-6-X6 & 388.096 & 91.936 & 89.540 \\
\hline T01-6-X7 & 413.430 & 91.912 & 89.510 \\
\hline T01-6-X8 & 438.866 & 91.909 & 89.470 \\
\hline T01-6-X9 & 464.208 & 91.872 & 89.460 \\
\hline T01-6-X10 & 489.597 & 91.633 & 89.430 \\
\hline T01-6-X11 & 515.039 & 91.442 & 89.430 \\
\hline T01-6-X12 & 540.175 & 91.311 & 89.440 \\
\hline T01-6-X13 & 565.505 & 91.286 & 89.450 \\
\hline T01-6-X14 & 590.888 & 91.054 & 89.490 \\
\hline T01-6-X15 & 616.332 & 90.888 & 89.530 \\
\hline
\end{tabular}


Table B.7. Specimen T01, perimeter face $P_{7}$ rotational angle: $85.396^{\circ}$.

\begin{tabular}{|l|c|c|c|}
\hline Marker ID & $\begin{array}{c}\text { Axial } \\
\text { direction } \\
\text { of the tube } \\
(\mathbf{m m}) \\
{[\mathbf{x}]}\end{array}$ & $\begin{array}{c}\text { Variable } \\
\text { distance } \\
\text { from ref. } \\
(\mathbf{m m}) \\
{[\mathbf{y}]}\end{array}$ & $\begin{array}{c}\text { Surface } \\
\text { normal } \\
\text { distance } \\
(\mathbf{m m}) \\
{[\mathbf{z}]}\end{array}$ \\
\hline T01-7-X1 & 261.155 & 92.660 & 89.740 \\
\hline T01-7-X2 & 286.711 & 92.727 & 89.690 \\
\hline T01-7-X3 & 312.095 & 92.519 & 89.630 \\
\hline T01-7-X4 & 337.354 & 92.502 & 89.620 \\
\hline T01-7-X5 & 362.915 & 92.554 & 89.560 \\
\hline T01-7-X6 & 388.304 & 92.333 & 89.520 \\
\hline T01-7-X7 & 413.641 & 92.315 & 89.490 \\
\hline T01-7-X8 & 438.804 & 92.207 & 89.460 \\
\hline T01-7-X9 & 464.144 & 92.171 & 89.430 \\
\hline T01-7-X10 & 489.535 & 91.931 & 89.400 \\
\hline T01-7-X11 & 514.978 & 91.736 & 89.400 \\
\hline T01-7-X12 & 540.224 & 91.753 & 89.410 \\
\hline T01-7-X13 & 565.552 & 91.700 & 89.440 \\
\hline T01-7-X14 & 590.932 & 91.442 & 89.470 \\
\hline T01-7-X15 & 616.377 & 91.239 & 89.510 \\
\hline
\end{tabular}

Table B.9. Specimen T22, perimeter face $P_{1}$ rotational angle: $0.000^{\circ}$.

\begin{tabular}{|l|c|c|c|}
\hline Marker ID & $\begin{array}{c}\text { Axial } \\
\text { direction } \\
\text { of the tube } \\
(\mathbf{m m}) \\
{[\mathbf{x}]}\end{array}$ & $\begin{array}{c}\text { Variable } \\
\text { distance } \\
\text { from ref. } \\
(\mathbf{m m}) \\
{[\mathbf{y}]}\end{array}$ & $\begin{array}{c}\text { Surface } \\
\text { normal } \\
\text { distance } \\
(\mathbf{m m}) \\
{[\mathbf{z}]}\end{array}$ \\
\hline T22-1-X1 & 261.561 & 92.661 & 89.572 \\
\hline T22-1-X2 & 287.156 & 92.710 & 89.602 \\
\hline T22-1-X3 & 312.407 & 92.662 & 89.632 \\
\hline T22-1-X4 & 337.934 & 92.509 & 89.662 \\
\hline T22-1-X5 & 363.205 & 92.241 & 89.682 \\
\hline T22-1-X6 & 388.791 & 92.276 & 89.732 \\
\hline T22-1-X7 & 414.059 & 92.179 & 89.672 \\
\hline T22-1-X8 & 439.589 & 91.985 & 89.652 \\
\hline T22-1-X9 & 464.391 & 92.210 & 89.602 \\
\hline T22-1-X10 & 489.914 & 92.028 & 89.572 \\
\hline T22-1-X11 & 515.172 & 91.956 & 89.512 \\
\hline T22-1-X12 & 540.768 & 91.980 & 89.452 \\
\hline T22-1-X13 & 565.930 & 91.781 & 89.392 \\
\hline T22-1-X14 & 591.184 & 91.666 & 89.342 \\
\hline T22-1-X15 & 616.792 & 91.666 & 89.302 \\
\hline
\end{tabular}

Table B.8. Specimen T01, perimeter face $P_{8}$ rotational angle: $41.996^{\circ}$.

\begin{tabular}{|l|c|c|c|}
\hline Marker ID & $\begin{array}{c}\text { Axial } \\
\text { direction } \\
\text { of the tube } \\
(\mathbf{m m}) \\
{[\mathbf{x}]}\end{array}$ & $\begin{array}{c}\text { Variable } \\
\text { distance } \\
\text { from ref. } \\
(\mathbf{m m}) \\
{[\mathbf{y}]}\end{array}$ & $\begin{array}{c}\text { Surface } \\
\text { normal } \\
\text { distance } \\
(\mathbf{m m}) \\
{[\mathbf{z}]}\end{array}$ \\
\hline T01-8-X1 & 261.080 & 92.660 & 89.650 \\
\hline T01-8-X2 & 286.638 & 92.725 & 89.610 \\
\hline T01-8-X3 & 312.025 & 92.516 & 89.560 \\
\hline T01-8-X4 & 337.337 & 92.458 & 89.530 \\
\hline T01-8-X5 & 362.898 & 92.514 & 89.520 \\
\hline T01-8-X6 & 388.287 & 92.301 & 89.490 \\
\hline T01-8-X7 & 413.626 & 92.297 & 89.460 \\
\hline T01-8-X8 & 438.929 & 92.049 & 89.430 \\
\hline T01-8-X9 & 464.276 & 92.045 & 89.390 \\
\hline T01-8-X10 & 489.667 & 91.837 & 89.360 \\
\hline T01-8-X11 & 515.235 & 91.896 & 89.340 \\
\hline T01-8-X12 & 540.141 & 91.789 & 89.340 \\
\hline T01-8-X13 & 565.476 & 91.740 & 89.340 \\
\hline T01-8-X14 & 590.861 & 91.480 & 89.350 \\
\hline T01-8-X15 & 616.430 & 91.500 & 89.370 \\
\hline
\end{tabular}

Table B.10. Specimen T22, perimeter face $P_{2}$ rotational angle: $317.307^{\circ}$.

\begin{tabular}{|l|c|c|c|}
\hline Marker ID & $\begin{array}{c}\text { Axial } \\
\text { direction } \\
\text { of the tube } \\
(\mathbf{m m}) \\
{[\mathbf{x}]}\end{array}$ & $\begin{array}{c}\text { Variable } \\
\text { distance } \\
\text { from ref. } \\
(\mathbf{m m}) \\
{[\mathbf{y}]}\end{array}$ & $\begin{array}{c}\text { Surface } \\
\text { normal } \\
\text { distance } \\
\text { (mm) } \\
{[\mathbf{z}]}\end{array}$ \\
\hline T22-2-X1 & 261.351 & 92.661 & 89.690 \\
\hline T22-2-X2 & 286.859 & 92.601 & 89.740 \\
\hline T22-2-X3 & 312.105 & 92.525 & 89.780 \\
\hline T22-2-X4 & 337.498 & 92.342 & 89.810 \\
\hline T22-2-X5 & 363.001 & 92.271 & 89.840 \\
\hline T22-2-X6 & 388.258 & 92.188 & 89.850 \\
\hline T22-2-X7 & 413.781 & 92.005 & 89.850 \\
\hline T22-2-X8 & 438.721 & 92.044 & 89.820 \\
\hline T22-2-X9 & 464.248 & 91.840 & 89.780 \\
\hline T22-2-X10 & 489.509 & 91.748 & 89.730 \\
\hline T22-2-X11 & 515.022 & 91.657 & 89.660 \\
\hline T22-2-X12 & 540.101 & 91.451 & 89.590 \\
\hline T22-2-X13 & 565.624 & 91.243 & 89.527 \\
\hline T22-2-X14 & 590.877 & 91.145 & 89.460 \\
\hline T22-2-X15 & 616.398 & 91.057 & 89.370 \\
\hline
\end{tabular}


Table B.11. Specimen T22, perimeter face $P_{3}$ rotational angle: $271.586^{\circ}$.

\begin{tabular}{|l|c|c|c|}
\hline Marker ID & $\begin{array}{c}\text { Axial } \\
\text { direction } \\
\text { of the tube } \\
(\mathbf{m m}) \\
{[\mathbf{x}]}\end{array}$ & $\begin{array}{c}\text { Variable } \\
\text { distance } \\
\text { from ref. } \\
(\mathbf{m m}) \\
{[\mathbf{y}]}\end{array}$ & $\begin{array}{c}\text { Surface } \\
\text { normal } \\
\text { distance } \\
(\mathbf{m m}) \\
{[\mathbf{z}]}\end{array}$ \\
\hline T22-3-X1 & 261.481 & 92.661 & 89.670 \\
\hline T22-3-X2 & 286.991 & 92.571 & 89.680 \\
\hline T22-3-X3 & 312.236 & 92.472 & 89.700 \\
\hline T22-3-X4 & 337.354 & 92.383 & 89.710 \\
\hline T22-3-X5 & 362.864 & 92.312 & 89.720 \\
\hline T22-3-X6 & 388.116 & 92.247 & 89.710 \\
\hline T22-3-X7 & 413.635 & 92.065 & 89.710 \\
\hline T22-3-X8 & 438.854 & 92.113 & 89.670 \\
\hline T22-3-X9 & 464.387 & 91.915 & 89.620 \\
\hline T22-3-X10 & 489.645 & 91.813 & 89.580 \\
\hline T22-3-X11 & 515.157 & 91.726 & 89.520 \\
\hline T22-3-X12 & 540.202 & 91.298 & 89.460 \\
\hline T22-3-X13 & 565.708 & 91.149 & 89.390 \\
\hline T22-3-X14 & 590.949 & 91.100 & 89.350 \\
\hline T22-3-X15 & 616.451 & 91.065 & 89.260 \\
\hline
\end{tabular}

Table B.13. Specimen T22, perimeter face $P_{5}$ rotational angle: $176^{\circ}$.

\begin{tabular}{|l|c|c|c|}
\hline Marker ID & $\begin{array}{c}\text { Axial } \\
\text { direction } \\
\text { of the tube } \\
(\mathbf{m m}) \\
{[\mathbf{x}]}\end{array}$ & $\begin{array}{c}\text { Variable } \\
\text { distance } \\
\text { from ref. } \\
(\mathbf{m m}) \\
{[\mathbf{y}]}\end{array}$ & $\begin{array}{c}\text { Surface } \\
\text { normal } \\
\text { distance } \\
(\mathbf{m m}) \\
{[\mathbf{z}]}\end{array}$ \\
\hline T22-5-X1 & 261.285 & 92.661 & 89.710 \\
\hline T22-5-X2 & 286.804 & 92.575 & 89.610 \\
\hline T22-5-X3 & 312.055 & 92.489 & 89.540 \\
\hline T22-5-X4 & 337.429 & 92.198 & 89.440 \\
\hline T22-5-X5 & 362.949 & 92.136 & 89.380 \\
\hline T22-5-X6 & 388.204 & 92.057 & 89.320 \\
\hline T22-5-X7 & 413.711 & 91.878 & 89.290 \\
\hline T22-5-X8 & 438.657 & 92.020 & 89.260 \\
\hline T22-5-X9 & 464.174 & 91.805 & 89.230 \\
\hline T22-5-X10 & 489.431 & 91.690 & 89.220 \\
\hline T22-5-X11 & 514.956 & 91.589 & 89.200 \\
\hline T22-5-X12 & 540.030 & 91.538 & 89.230 \\
\hline T22-5-X13 & 565.544 & 91.376 & 89.220 \\
\hline T22-5-X14 & 590.789 & 91.309 & 89.240 \\
\hline T22-5-X15 & 616.314 & 91.259 & 89.260 \\
\hline
\end{tabular}

Table B.12 Specimen T22, perimeter face $P_{4}$ rotational angle: $226.967^{\circ}$.

\begin{tabular}{|l|c|c|c|}
\hline Marker ID & $\begin{array}{c}\text { Axial } \\
\text { direction } \\
\text { of the tube } \\
(\mathbf{m m}) \\
{[\mathbf{x}]}\end{array}$ & $\begin{array}{c}\text { Variable } \\
\text { distance } \\
\text { from ref. } \\
(\mathbf{m m}) \\
{[\mathbf{y}]}\end{array}$ & $\begin{array}{c}\text { Surface } \\
\text { normal } \\
\text { distance } \\
(\mathbf{m m}) \\
{[\mathbf{z}]}\end{array}$ \\
\hline T22-4-X1 & 261.568 & 92.661 & 89.720 \\
\hline T22-4-X2 & 287.081 & 92.562 & 89.670 \\
\hline T22-4-X3 & 312.333 & 92.457 & 89.630 \\
\hline T22-4-X4 & 337.545 & 92.223 & 89.600 \\
\hline T22-4-X5 & 363.062 & 92.161 & 89.570 \\
\hline T22-4-X6 & 388.318 & 92.085 & 89.550 \\
\hline T22-4-X7 & 413.835 & 91.909 & 89.520 \\
\hline T22-4-X8 & 438.483 & 92.014 & 89.490 \\
\hline T22-4-X9 & 464.007 & 91.807 & 89.440 \\
\hline T22-4-X10 & 489.268 & 91.724 & 89.410 \\
\hline T22-4-X11 & 514.787 & 91.638 & 89.370 \\
\hline T22-4-X12 & 540.288 & 91.375 & 89.370 \\
\hline T22-4-X13 & 565.805 & 91.222 & 89.320 \\
\hline T22-4-X14 & 591.059 & 91.159 & 89.310 \\
\hline T22-4-X15 & 616.574 & 91.118 & 89.260 \\
\hline
\end{tabular}

Table B.14. Specimen T22, perimeter face $P_{6}$ rotational angle: $131.712^{\circ}$.

\begin{tabular}{|l|c|c|c|}
\hline Marker ID & $\begin{array}{c}\text { Axial } \\
\text { direction } \\
\text { of the tube } \\
(\mathbf{m m}) \\
{[\mathbf{x}]}\end{array}$ & $\begin{array}{c}\text { Variable } \\
\text { distance } \\
\text { from ref. } \\
(\mathbf{m m}) \\
{[\mathbf{y}]}\end{array}$ & $\begin{array}{c}\text { Surface } \\
\text { normal } \\
\text { distance } \\
(\mathbf{m m}) \\
{[\mathbf{z}]}\end{array}$ \\
\hline T22-6-X1 & 261.768 & 92.661 & 89.810 \\
\hline T22-6-X2 & 287.290 & 92.605 & 89.700 \\
\hline T22-6-X3 & 312.543 & 92.535 & 89.590 \\
\hline T22-6-X4 & 337.773 & 92.538 & 89.500 \\
\hline T22-6-X5 & 363.299 & 92.457 & 89.420 \\
\hline T22-6-X6 & 388.561 & 92.371 & 89.350 \\
\hline T22-6-X7 & 414.068 & 92.185 & 89.310 \\
\hline T22-6-X8 & 438.955 & 92.252 & 89.280 \\
\hline T22-6-X9 & 464.471 & 92.064 & 89.240 \\
\hline T22-6-X10 & 489.730 & 91.970 & 89.230 \\
\hline T22-6-X11 & 515.259 & 91.882 & 89.230 \\
\hline T22-6-X12 & 540.078 & 91.838 & 89.250 \\
\hline T22-6-X13 & 565.587 & 91.645 & 89.270 \\
\hline T22-6-X14 & 590.832 & 91.552 & 89.310 \\
\hline T22-6-X15 & 616.356 & 91.472 & 89.350 \\
\hline
\end{tabular}


Table B.15 Specimen T22, perimeter face $P_{7}$ rotational angle: $85.285^{\circ}$.

\begin{tabular}{|l|c|c|c|}
\hline Marker ID & $\begin{array}{c}\text { Axial } \\
\text { direction } \\
\text { of the tube } \\
(\mathbf{m m}) \\
{[\mathbf{x}]}\end{array}$ & $\begin{array}{c}\text { Variable } \\
\text { distance } \\
\text { from ref. } \\
(\mathbf{m m}) \\
{[\mathbf{y}]}\end{array}$ & $\begin{array}{c}\text { Surface } \\
\text { normal } \\
\text { distance } \\
(\mathbf{m m}) \\
{[\mathbf{z}]}\end{array}$ \\
\hline T22-7-X1 & 261.371 & 92.661 & 89.840 \\
\hline T22-7-X2 & 286.897 & 92.633 & 89.750 \\
\hline T22-7-X3 & 312.148 & 92.587 & 89.670 \\
\hline T22-7-X4 & 337.391 & 92.407 & 89.580 \\
\hline T22-7-X5 & 362.916 & 92.328 & 89.520 \\
\hline T22-7-X6 & 388.172 & 92.245 & 89.460 \\
\hline T22-7-X7 & 413.681 & 92.061 & 89.430 \\
\hline T22-7-X8 & 438.374 & 92.207 & 89.400 \\
\hline T22-7-X9 & 463.897 & 92.038 & 89.360 \\
\hline T22-7-X10 & 489.153 & 91.968 & 89.340 \\
\hline T22-7-X11 & 514.688 & 91.907 & 89.370 \\
\hline T22-7-X12 & 539.969 & 91.865 & 89.330 \\
\hline T22-7-X13 & 565.477 & 91.655 & 89.350 \\
\hline T22-7-X14 & 590.729 & 91.549 & 89.370 \\
\hline T22-7-X15 & 616.255 & 91.460 & 89.390 \\
\hline
\end{tabular}

Table B.16. Specimen T22, perimeter face $P_{8}$ rotational angle: $40.057^{\circ}$.

\begin{tabular}{|l|c|c|c|}
\hline Marker ID & $\begin{array}{c}\text { Axial } \\
\text { direction } \\
\text { of the tube } \\
(\mathbf{m m}) \\
{[\mathbf{x}]}\end{array}$ & $\begin{array}{c}\text { Variable } \\
\text { distance } \\
\text { from ref. } \\
(\mathbf{m m}) \\
{[\mathbf{y}]}\end{array}$ & $\begin{array}{c}\text { Surface } \\
\text { normal } \\
\text { distance } \\
\text { (mm) } \\
{[\mathbf{z}]}\end{array}$ \\
\hline T22-8-X1 & 261.335 & 92.661 & 89.800 \\
\hline T22-8-X2 & 286.847 & 92.633 & 89.770 \\
\hline T22-8-X3 & 312.097 & 92.600 & 89.740 \\
\hline T22-8-X4 & 337.700 & 92.471 & 89.700 \\
\hline T22-8-X5 & 363.214 & 92.402 & 89.680 \\
\hline T22-8-X6 & 388.470 & 92.318 & 89.650 \\
\hline T22-8-X7 & 413.983 & 92.136 & 89.630 \\
\hline T22-8-X8 & 439.011 & 92.159 & 89.590 \\
\hline T22-8-X9 & 464.535 & 91.998 & 89.570 \\
\hline T22-8-X10 & 489.789 & 91.934 & 89.520 \\
\hline T22-8-X11 & 515.306 & 91.880 & 89.480 \\
\hline T22-8-X12 & 539.740 & 91.601 & 89.470 \\
\hline T22-8-X13 & 565.252 & 91.373 & 89.450 \\
\hline T22-8-X14 & 590.498 & 91.242 & 89.430 \\
\hline T22-8-X15 & 616.020 & 91.129 & 89.430 \\
\hline
\end{tabular}


